\title{
Preparation of ZnO Hybrid Nanoparticles by ATRP
}

Hangjun Ding ${ }^{\mathrm{a}}$, Jiajun Yan ${ }^{\mathrm{a}}$, Zongyu Wang ${ }^{\mathrm{a}}$, Guojun Xie ${ }^{\mathrm{a}}$, Clare Mahoney ${ }^{\mathrm{b}, \mathrm{e}}$, Rachel Ferebee ${ }^{\mathrm{b}, \mathrm{f}}$, Mingjiang Zhong ${ }^{\mathrm{a}, \mathrm{g}}$, William F. M. Daniel ${ }^{\mathrm{c}}$, Joanna Pietrasik ${ }^{\mathrm{d}}$, Sergei S. Sheiko ${ }^{\mathrm{c}}$, Christopher J.

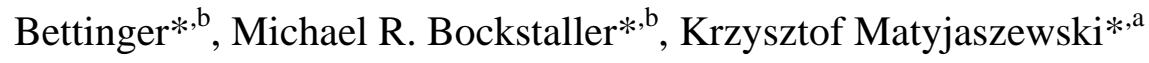

${ }^{\mathrm{a}}$ Department of Chemistry and ${ }^{\mathrm{b}}$ Department of Materials Science \& Engineering, Carnegie Mellon University, 5000 Forbes Avenue, Pittsburgh, Pennsylvania 15213, USA

${ }^{\mathrm{c}}$ Department of Chemistry, University of North Carolina at Chapel Hill, Chapel Hill, North Carolina 27599-3290, USA

d Institute of Polymer and Dye Technology, Lodz University of Technology, Stefanowskiego 12/16, 90-924 Lodz, Poland

${ }^{\mathrm{e}}$ Present Address: Materials and Manufacturing Directorate, Air Force Research Laboratory, 2941

Hobson Way, B654/R331 Wright Pattern AFB, Ohio 45433-7750, USA

${ }^{\mathrm{f}}$ Present Address: L’Oreal, 159 Terminal Ave, Clark, New Jersey 07066, USA

${ }^{\mathrm{g}}$ Present Address: Department of Chemical \& Environmental Engineering, Yale University, 17

Hillhouse Avenue, New Haven, Connecticut 06511, USA

KEYWORDS: ZnO nanoparticle, SI-ATRP, polymer templates, star templates 


\section{GRAPHIC ABSTRACT}

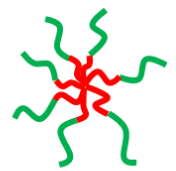

PAA- $b$-PSAN/PS

grafted copolymer

Zno precursor

"grafted-copolymer template"

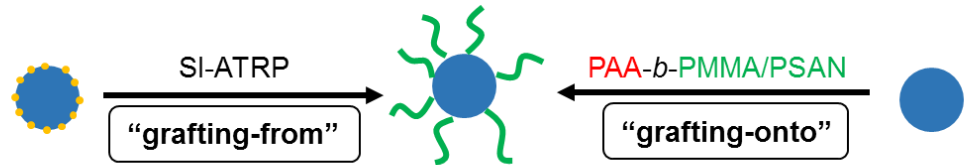

Initiator-modified $\mathrm{ZnO} \quad \mathrm{ZnO}$ hybrid particle

Pristine $\mathrm{ZnO}$ 


\section{ABSTRACT:}

Zinc oxide $(\mathrm{ZnO})$ is a wide bandgap semiconductor material that has attracted widespread interest as particle filler in polymer nanocomposite materials. However, its applications have been hindered by the limited dispersibility and surface-modification techniques. Herein, three distinct approaches for the synthesis of polymer-tethered $\mathrm{ZnO}$ hybrid materials are compared in terms of uniformity and yield of the particle-brush product: "grafting-from", "grafting-onto", and "grafted-copolymer template" methods. In the "grafting-from" method, pristine $\mathrm{ZnO}$ nanoparticles (NP) were first functionalized with atom transfer radical polymerization (ATRP) initiators followed by grafting-from process to form poly(methyl methacrylate) (PMMA) or poly(styrene-co-acrylonitrile) (PSAN) tethered polymer chains. In the "grafting-onto" method, PMMA- $b$-PAA (poly[acrylic acid]) and PSAN- $b$-PAA diblock copolymers were prepared and attached onto the surface of ZnO NPs using sonication bath. For the "grafted-copolymer template" method, PSAN- $b$-PtBA-Br (poly[tert-butyl acrylate]-Br) macroinitiators were crosslinked with divinylbenzene (DVB) to form PSAN- $b$-PtBA-PDVB core-shell star polymers. After hydrolysis to form PSAN-b-PAA-PDVB star polymers, the functional stars were used as polymer templates for the synthesis of $\mathrm{ZnO}$ NPs within the PAA-core of the stars. Core-shell molecular bottlebrushes with PAA- $b$-PS block-copolymer side chains were also used as anisotropic analogues of star template to prepared worm-like $\mathrm{ZnO}$ particles. Several $\mathrm{ZnO}$ precursors, zinc nitrite, zinc 2-ethylhexanoate, and zinc acetate were evaluated as precursors of $\mathrm{ZnO}$. Conditions were identified that enable the synthesis of polymer-tethered $\mathrm{ZnO}$ with excellent size uniformity and dispersion characteristics using the star-template method. 


\section{Introduction}

$\mathrm{ZnO}$ nanoparticles (NP) display high thermal conductivity, UV absorption, high refractive index, and photo-catalytic properties. These unique properties resulted in their evaluation in a number of applications, including cosmetic products, electronic sensors, food products, or cancer theranostics.[1-3] To enable these applications, the development of ligand modification strategies to facilitate the stabilization of particles and their processing into functional material forms, is required. Polymeric ligands have attracted particular attention because of their effectiveness in stabilizing particle dispersions (both in liquid and solid matrix) and to enable the processing of "matrix-free" hybrid materials.[4-9]

Two major routes for tethering of polymer chains to the surface of particles are "grafting-onto" and "grafting-from".[10-12] The "grafting-onto" process involves the coupling of pre-synthesized polymers to functional groups that are exposed at the surface. The principal advantage of "grafting-onto" modification is the simplicity and scalability of the process; however, the low density of tethered chains limits the overall control of material properties. In contrast, the "grafting-from" of polymer chains involves two steps: the binding of low-molecular-weight initiating groups to the particle surface and subsequent formation of polymers via controlled radical polymerization. Because of the low molecular weight initiating groups, the "grafting-from" process affords higher grafting densities and better control of the physicochemical properties of polymer-tethered particles.[13] One of the most established approaches to form hybrid particles using the "grafting-from" method, is surface-initiated atom transfer radical polymerization (SI-ATRP).[10-12] Advantages of SI-ATRP include excellent control of molecular characteristics as well as the diverse range of accessible monomer compositions.[10, 11, 14-16] Suitable coupling agents are necessary for efficient surface modification of nanoparticles with initiators. However, it is difficult to modify the surface of $\mathrm{ZnO} \mathrm{NP}$ due to its inert nature and limited functionality at the surface. Modifications of $\mathrm{ZnO}$ surfaces through thiol,[17] carboxylic acid,[18] and silane coupling agents[19] were reported, but these methods produce $\mathrm{ZnO}$ NPs with limited dispersibility. 
An alternative approach to fabricate inorganic/polymer hybrid materials is by templating of grafted-copolymer "nanoreactors".[20-23] A grafted copolymer molecule contains multiple linear polymer arms connected to a backbone (one-dimensional, also called molecular bottlebrush) or at a central core (zero-dimensional, also called star polymer). Star polymers with block copolymer arms are useful nanoreactors for the synthesis of inorganic materials because they form thermodynamically stable unimolecular micelles that enable high uniformity of particle products. Previous studies demonstrated successful fabrication of star polymer nanoreactors via ATRP of block copolymers from a multifunctional core (“core-first").[20] A large variety of uniform nanoscale polymer/inorganic hybrid materials were successfully synthesized within the star polymer nanoreactors. These well-defined hybrid materials were demonstrated to be applicable to a broad range of fields.[24-31] One convenient method to form star polymers is to crosslink a functional chain end on pre-existing polymeric chains to form the core of the star ("arm-first").[32] The "arm-first" approach enabled higher graft density in star polymers, and consequently in the hybrid nanoparticles. In addition to spherical star polymer, molecular bottlebrushes were also used as single-molecule templates for fabricating one-dimensional nanostructures such as nanowires and nanotubes due to their worm-like morphologies.[22, 33-41] Nanoparticles were prepared by in situ conversion of the inorganic precursors immobilized within the functional block via a specific bonding.[42] Advantages of the "grafted-copolymer nanoreactor" approach include high achievable particle size uniformity, variability of the resulting ligand composition, and good stability of the particle-polymer bonding. The methodology is particularly interesting for $\mathrm{ZnO}$ and other ceramic material systems for which covalent and/or dense tethering of ligands is limited by the particle surface chemistry.

Herein, we examined three methods for synthesis $\mathrm{ZnO}$ /polymer hybrid NPs: "grafting-from", "grafting-onto" and use of "grafted-copolymer templates". Each method was effective for the preparation of stable homogenous dispersions of $\mathrm{ZnO}$ NPs of different sizes in both solvents and polymer matrices. 


\section{Materials and methods}

\subsection{Materials}

All monomers: (2-trimetylsiloxy)ethyl methacrylate (HEMA-TMS, Scientific Polymer Products), tert-butyl acrylate ( $t \mathrm{BA}, 98 \%$ Aldrich), methyl methacrylate (MMA, 99\%, Aldrich), styrene (S, 99\%, Aldrich), acrylonitrile (AN, 99\%, Aldrich), and divinylbenzene (DVB, 80\%, Aldrich) were purified by passing through a column filled with basic alumina to remove the inhibitor. Copper (I) bromide $(\mathrm{CuBr}$, 98\%, Acros) was purified using literature procedures.[43] Tris[(2-pyridyl)methyl]amine (TPMA) was synthesized according to the previously published procedure.[44] Tri(2-dimethylaminoethyl)amine $\left(\mathrm{Me}_{6} \mathrm{TREN}, 99 \%\right.$, Alfa), zinc 2-ethylhexanoate $\left(\mathrm{Zn}(\mathrm{EH})_{2}, 80 \%\right.$ in mineral spirits, Alfa), hydrochloric acid ( $\mathrm{HCl}, 36.5-38.0 \%$, Sigma), zinc oxide nanopowder ( $\mathrm{ZnO}, 99.95 \%, 18 \mathrm{~nm}$, US-Nano), zinc nitrate hexahydrate $\left(\mathrm{Zn}\left(\mathrm{NO}_{3}\right)_{2}, 98 \%\right.$, Aldrich), sodium hydroxide $(\mathrm{NaOH}, 98 \%$, Aldrich), trifluoroacetic acid (TFA, 98\%, Alfa), anisole (99\%, Aldrich), methylene chloride (DCM, 99.5\%, Fisher), tetrahydrofuran (THF, 99\%, VWR), methanol (99\%, VWR), hexane (99\%, VWR), acetone (99\%, VWR), N,N-dimethylformamide (DMF, 99\%, VWR), ZnO dispersion(40 wt. \% in butyl acetate, Aldrich), $\alpha$-bromoisobutyryl bromide (2-BiB, Aldrich), ethyl 2-bromoisobutyrate (EBiB, 98\%, Aldrich), ethyl 2-bromophenylacetate (EBPA, 97\%, Aldrich), $\quad N, N, N^{\prime}, N^{\prime \prime}, N^{\prime \prime}$-pentamethyldiethylenetriamine (PMDETA, Aldrich), copper(II) bromide ( $\mathrm{CuBr}_{2}, 99 \%$, Aldrich), triethylamine (TEA, 98\%, Aldrich), diphenyl ether (DPE, 99\%, Aldrich), zinc acetate ( $\mathrm{Zn}(\mathrm{OAc}) 2,99.99 \%$, Aldrich), tin(II) 2-ethylhexanoate $\left(\mathrm{Sn}(\mathrm{EH})_{2}, 95 \%\right.$, Aldrich), 4,4'-dinonyl-2,2'-bipyridyne (dNbpy, 97\%, Aldrich), potassium fluoride (KF, 99\%, Aldrich), tetrabutylammonium fluoride (TBAF, 1.0 M in THF, Aldrich), 2,5-di-tert-butylphenol (DTBP, 99\%), trifluoroacetic acid (TFA, $\geq 98 \%, \quad$ Aldrich), and 2,2'-azobis(2-methylpropionitrile) (AIBN, 98\%, Aldrich) were used as received without further purification. 


\subsection{Synthesis of polymer grafted ZnO nanoparticles by the "grafting-from" method}

2.2.1 Functionalization of ZnO nanoparticles. PMMA and PSAN grafted $\mathrm{ZnO}$ nanoparticles were synthesized in two steps. In the initial step initiator functionalized $\mathrm{ZnO}(\mathrm{ZnO}-\mathrm{Br})$ nanoparticles were synthesized by adding $25 \mathrm{~g}$ of $\mathrm{ZnO}$ dispersion (40\% in butyl acetate) to $200 \mathrm{~mL}$ of dry THF in a round bottom flask, then TEA $(5.14 \mathrm{~mL}, 37 \mathrm{mmol})$ was added to the dispersion. The flask was sealed, transferred to an ice bath and stirred. 2-BiB $(4.56 \mathrm{~mL}, 37 \mathrm{mmol})$ was added dropwise to the reaction. The flask was stirred for another $48 \mathrm{~h}$ at room temperature. The product was washed 3 times with cold methanol and dried in air for $24 \mathrm{~h}$. After removal of all solvents, $\mathrm{ZnO}-\mathrm{Br}$ NPs were obtained.

\subsubsection{General example of surface initiated ATRP procedure. Synthesis of PMMA or PSAN using} activators regenerated by electron transfer (ARGET) ATRP from ZnO-Br.[45-47] The polymer brushes were grafted from the surface of initiator-modified zinc oxide nanoparticles using the following procedure: $1.0 \mathrm{~g} \mathrm{ZnO}-\mathrm{Br}$ nanoparticles, $\mathrm{Me}_{6} \mathrm{TREN}(0.038 \mathrm{~g}, 0.143 \mathrm{mmol}), 30 \mathrm{mM}$ solution of $\mathrm{CuBr}_{2}$ in DMF (1 mL, $0.030 \mathrm{mmol})$, anisole $(10 \mathrm{~mL})$, and, either MMA $(10 \mathrm{~mL}, 95 \mathrm{mmol})$ or St $(10.5 \mathrm{~mL}, 95$ mmol) and AN (3.7 mL, $57 \mathrm{mmol})$, were added to a $50 \mathrm{~mL}$ Schlenk flask equipped with a magnetic stir bar. The flask was sealed, and the resulting solution was bubbled with $\mathrm{N}_{2}$ for 30 minutes. $15 \mathrm{mM}$ of a solution of $\mathrm{Sn}(\mathrm{EH})_{2}$ in anisole $(1 \mathrm{~mL}, 0.015 \mathrm{mmol})$ was added to the flask to reduce a fraction of the $\mathrm{CuBr}_{2} / \mathrm{L}$ to the activator complex. The flask was then immersed in an oil bath set at $70{ }^{\circ} \mathrm{C}$, and the reaction mixture was kept under these conditions for the desired time, MMA system for $1 \mathrm{~h}$ while the SAN system for $24 \mathrm{~h}$. The reaction mixture was exposed to air to stop the reaction. Products were precipitated by addition of the solution to cold methanol. The samples were then centrifuged, and the products were redissolved in THF. The resulting suspension was cloudy and unstable. The samples were then centrifuged again to remove the insoluble impurities, which were non-functionalized pristine $\mathrm{ZnO}$ nanoparticles. The resulted solution of the polymer functionalized $\mathrm{ZnO}$ nanoparticles was concentrated and the particles precipitated by addition of the solution into methanol. Solid products were dried in air for further characterizations. 
2.2.2.1 General procedure for cleavage of polymer brushes from nanoparticles. $2 \mathrm{~mL}$ of 36.5-38.0\% $\mathrm{HCl}$ (aq.) solution were added to a $2 \mathrm{~mL}$ of solution of the particles in THF (ca. $10 \mathrm{mg}$ $\mathrm{mL}^{-1}$ ), and the reaction was allowed to stir at room temperature for $30 \mathrm{~min}$. The cleaved polymer was isolated by precipitation in cold methanol to remove the zinc salt and acid. After filtration, the remaining methanol was evaporated into the air.

\subsection{Synthesis of polymer grafted ZnO nanoparticles by "grafting-onto" method}

\subsubsection{Synthesis of PMMA- $b$-PAA diblock copolymer.}

2.3.1.1 The initial PMMA-Br macroinitiator was synthesized using ARGET ATRP. EBPA (0.20 mL, $1.1 \mathrm{mmol}), \mathrm{MMA}(12.2 \mathrm{~mL}, 114 \mathrm{mmol}), \mathrm{CuBr}_{2}(1.3 \mathrm{mg}, 0.0057 \mathrm{mmol}), \mathrm{Me}_{6} \mathrm{TREN}(30 \mathrm{mg}, 1.1$ mmol) and DMF (0.4 mL) were mixed in a Schlenk flask. The reaction mixture was degassed by $\mathrm{N}_{2}$ bubbling for $25 \mathrm{~min}$. Meanwhile, a solution of $\mathrm{Sn}(\mathrm{EH})_{2}(28 \mathrm{mg}, 0.069 \mathrm{mmol})$ in anisole $(4.1 \mathrm{~mL})$ was degassed. Half of the $\operatorname{Sn}(\mathrm{EH})_{2}$ solution was injected into the reaction and the mixture was heated to 60 ${ }^{\circ} \mathrm{C}$ in oil bath. After $2.5 \mathrm{~h}$, the other half of the $\mathrm{Sn}(\mathrm{EH})_{2}$ solution was injected into the reaction. The progress of reaction was monitored with size exclusion chromatography (SEC) and ${ }^{1} \mathrm{H}$ nuclear magnetic resonance (NMR). At the desired conversion, the reaction was quenched by exposure to air and dilution with $10 \mathrm{~mL}$ THF. The PMMA-Br macroinitiator was isolated by precipitation in methanol.

2.3.1.2 Chain extension of PMMA-Br macroinitiator. PMMA-Br ( $2.0 \mathrm{~g}, 0.34 \mathrm{mmol}), t \mathrm{BA}(1.5$ $\mathrm{mL}, 10 \mathrm{mmol}), \mathrm{CuBr}_{2}(0.4 \mathrm{mg}, 0.002 \mathrm{mmol}), \mathrm{Me}_{6} \mathrm{TREN}(0.005 \mathrm{~mL}, 0.02 \mathrm{mmol})$, and anisole $(6.0 \mathrm{~mL})$ were mixed in a Schlenk flask. The reaction mixture was degassed by $\mathrm{N}_{2}$ bubbling for 15 min and then transferred to an oil bath set at $60^{\circ} \mathrm{C}$. The reaction was stirred for $2 \mathrm{~h}$ and quenched by addition of $5 \mathrm{~mL}$ THF and exposure to air. The mixture was passed through a flash column filled with neutral alumina to remove all traces of catalyst.

2.3.1.3 Hydrolysis of the PtBA segment. 2.0 g of PMMA- $b$-P $t$ BA diblock copolymer was dissolved in $20 \mathrm{~mL}$ DCM. $2.0 \mathrm{~mL}$ of TFA was added slowly to the reaction while the solution was vigorously 
stirred. The reaction was then stirred at room temperature for $48 \mathrm{~h}$. PMMA- $b$-PAA was isolated as a translucent solid after removal of solvent and acids in vacuo.

\subsubsection{Synthesis of PAA-b-PSAN diblock copolymer.}

2.3.2.1 Preparation of PtBA macroinitiator. EBiB (1.0 g, $6.8 \mathrm{mmol}), t \mathrm{BA}(10.0 \mathrm{~mL}, 68.2 \mathrm{mmol})$, $\mathrm{CuBr}_{2}(7.6 \mathrm{mg}, 0.03 \mathrm{mmol}), \mathrm{Me}_{6} \mathrm{TREN}(0.091 \mathrm{~mL}, 0.34 \mathrm{mmol})$, and anisole $(10 \mathrm{~mL})$ were mixed in a Schlenk flask. The reaction mixture was degassed by $\mathrm{N}_{2}$ bubbling for 40 min and was then transferred to an oil bath set at $60{ }^{\circ} \mathrm{C}$. The reaction was stirred for $2 \mathrm{~h}$ and quenched by additional $30 \mathrm{~mL}$ THF and exposure to air. The mixture was passed through a flash column filled with neutral alumina to remove residual catalyst.

2.3.2.2 Chain extension of the PtBA-Br macroinitiator with $\mathrm{SAN}$ copolymer. $\mathrm{P} t \mathrm{BA}-\mathrm{Br}(2.0 \mathrm{~g}$, $0.95 \mathrm{mmol}), \mathrm{S}(16.4 \mathrm{~mL}, 142 \mathrm{mmol}), \mathrm{AN}(3.6 \mathrm{~mL}, 9.5 \mathrm{mmol}), \mathrm{CuBr}_{2}(5.3 \mathrm{mg}, 0.024 \mathrm{mmol}), \mathrm{Me}_{6} \mathrm{TREN}$ (6.3 mg, $0.24 \mathrm{mmol}$ ) were mixed in a Schlenk flask. The reaction mixture was degassed by $\mathrm{N}_{2}$ bubbling for $30 \mathrm{~min}$. Meanwhile, a solution of $\mathrm{Sn}(\mathrm{EH})_{2}(58 \mathrm{mg}, 0.24 \mathrm{mmol})$ in anisole $(5.5 \mathrm{~mL})$ was degassed. The $\mathrm{Sn}(\mathrm{EH})_{2}$ solution was injected into the reaction and the mixture was heated to $60{ }^{\circ} \mathrm{C}$ in an oil bath. The progress of the reaction was monitored with SEC and ${ }^{1} \mathrm{H}$ NMR. At the desired conversion, the reaction was quenched by exposure to air and dilution with $15 \mathrm{~mL}$ THF. The mixture was passed through a flash column filled with neutral alumina to remove catalyst.

2.3.2.3 Hydrolysis of the PtBA segment. $2.0 \mathrm{~g}$ of PtBA- $b$-PSAN diblock copolymer were dissolved in $20 \mathrm{~mL}$ DCM. The solution was vigorously stirred and $2.0 \mathrm{~mL}$ of TFA was added slowly to the reaction. The reaction mixture was stirred at room temperature for $48 \mathrm{~h}$. The PAA- $b$-PSAN diblock copolymer was obtained as a translucent solid after removal of solvent and acids in vacuo.

2.3.3 “Grafting-onto" ZnO nanoparticles. $2.0 \mathrm{~g} \mathrm{ZnO}$ nanopowder (US-Nano, $18 \mathrm{~nm}$ ) and $2.0 \mathrm{~g}$ PAA-based diblock copolymer were dissolved in $20 \mathrm{~mL}$ THF. The mixture was predispersed with a Misonic S-4000 ultrasonic liquid processer with a \#419 Microtip probe at amplitude = 70 for 5 min with $1 \mathrm{~s}$ interval every second of sonication in an ice bath. The predipersed mixture was then sonicated in a Bransonic CPX1800H bath sonicator at $50^{\circ} \mathrm{C}$ for $48 \mathrm{~h}$. The polymer modified $\mathrm{ZnO}$ nanoparticles were 
obtained by centrifuging the white dispersion at $14,000 \mathrm{rpm}$ for $5 \mathrm{~min}$. The nanoparticles were redispersed into THF with a Vortex mixer and centrifuged for 3 cycles to remove untethered polymer.

\subsection{Synthesis of polymer grafted ZnO nanoparticles by the "grafted-copolymer template" method}

2.4.1 Synthesis of PSAN-b-PAA-PDVB star polymers. The process for synthesis of PSAN- $b$-PAA-PDVB star polymers consists of four steps: synthesis of PSAN-Br macroinitiators (MIs), synthesis of PSAN- $b$-P $t$ BA-Br block copolymer MIs, synthesis of PSAN- $b$-P $t$ BA-PDVB star polymers, and hydrolysis of PSAN- $b$-PtBA-PDVB star polymers. (Scheme 1)

Scheme 1. Synthesis of PSAN-b-PAA-PDVB star polymer templates
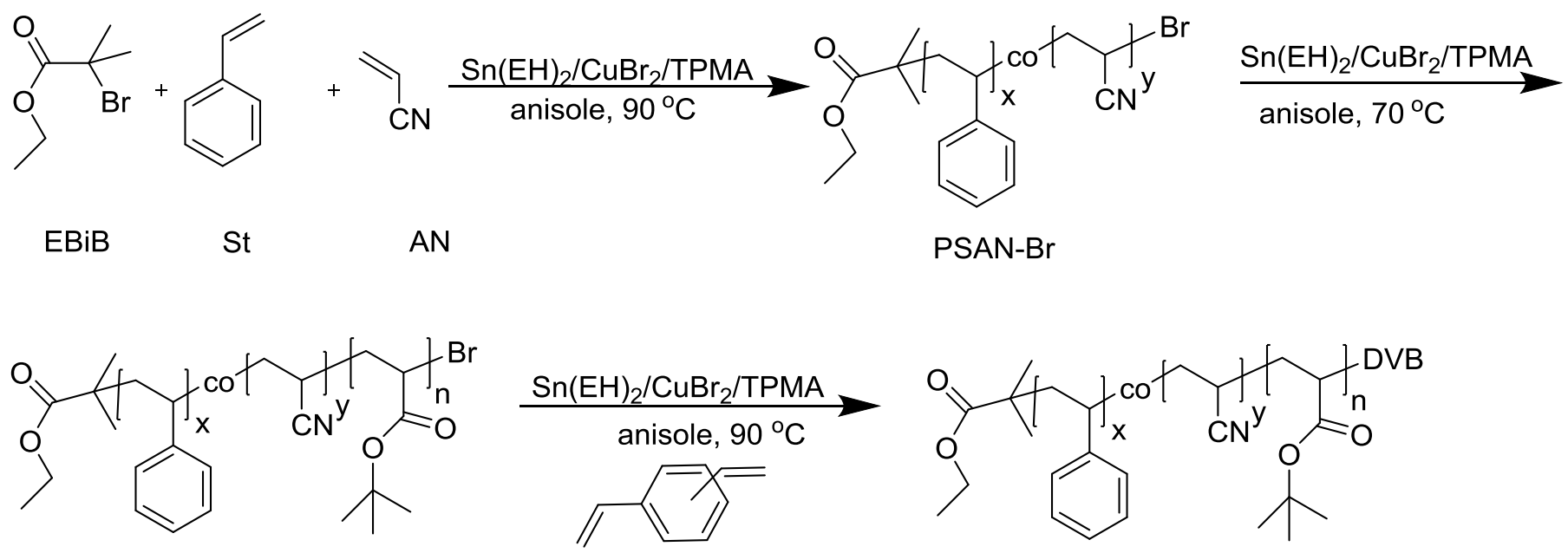

PSAN- $b-\mathrm{P} t \mathrm{BA}-\mathrm{Br}$

PSAN-b-PtBA-PDVB star polymer

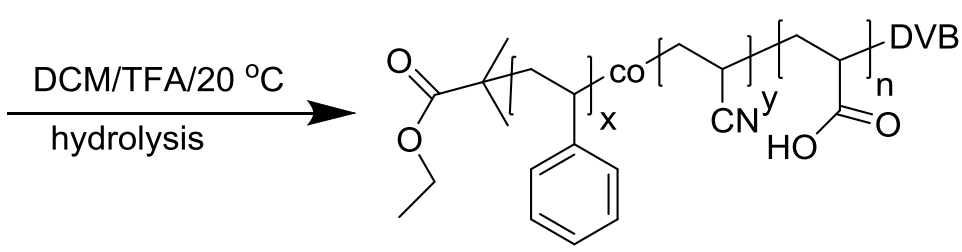

PSAN-b-PAA-PDVB star polymer

2.4.1.1 PSAN-Br MIs were synthesized first via ARGET ATRP. A clean dry $200 \mathrm{~mL}$ Schlenk flask was charged with $\mathrm{CuBr}_{2}(9.6 \mathrm{mg}, 0.43 \mathrm{mmol})$, TPMA (627.2 mg, $\left.2.1 \mathrm{mmol}\right), \mathrm{S}$ (60 mL, $\left.540 \mathrm{mmol}\right)$, 
AN (20 mL, $324 \mathrm{mmol})$ and anisole $(20 \mathrm{~mL})$. The flask was subjected to sonication and was then bubbled with $\mathrm{N}_{2}$ for 30 min to remove $\mathrm{O}_{2}$. $\mathrm{EBiB}$ initiator $(1.05 \mathrm{~mL}, 5.4 \mathrm{mmol})$ was then added to the flask. A mixture of $\mathrm{Sn}(\mathrm{EH})_{2}(0.17 \mathrm{~mL})$ and anisole $(10 \mathrm{~mL})$ was deoxygenated by bubbling $\mathrm{N}_{2}$ for 5-10 min, and $1 \mathrm{~mL}$ of the mixture was added to the reaction flask to reduce some of the $\mathrm{Cu}(\mathrm{II})$ catalyst complex and initiate polymerization. Then the flask was immersed into an oil bath set at $70^{\circ} \mathrm{C}$. At timed intervals, samples were withdrawn and diluted with THF for SEC (calibrated to PS standards) and with

$\mathrm{CDCl}_{3}$ for ${ }^{1} \mathrm{H} \mathrm{NMR}$ analysis. The reaction mixture was kept under these conditions for the desired time and then it was exposed to air to stop the reaction. The product was precipitated by addition of the reaction mixture to cold methanol to remove catalyst, and dried in air.

\subsubsection{Chain extension of the PSAN-Br macroinitiator and synthesis of a PSAN-b-PtBA-Br}

block copolymer. The PSAN ${ }_{70}-\mathrm{Br}$ initiator $\left(M_{\mathrm{n}}=5800 \mathrm{~g} / \mathrm{mol}, 10 \mathrm{~g}, 1.8 \mathrm{mmol}\right), t \mathrm{BA}(60 \mathrm{~mL}, 545 \mathrm{mmol})$, $\mathrm{CuBr}_{2}(23.1 \mathrm{mg}, 0.14 \mathrm{mmol})$, TPMA (150.5 mg, $\left.0.68 \mathrm{mmol}\right)$, and anisole $(25 \mathrm{~mL})$ were added to a clean dry $50 \mathrm{~mL}$ Schlenk flask. The flask was sealed with a glass stopper and bubbled with $\mathrm{N}_{2}$ for 30 min. A mixture of $\mathrm{Sn}(\mathrm{EH})_{2}(0.59 \mathrm{~mL})$ and anisole $(10 \mathrm{~mL})$ was deoxygenated by bubbling $\mathrm{N}_{2}$ for 5-10 min, and $0.1 \mathrm{~mL}$ of the solution was added to the reaction flask to reduce some of the $\mathrm{Cu}(\mathrm{II})$ catalyst complex and initiate polymerization. The flask was immersed in an oil bath set at $70{ }^{\circ} \mathrm{C}$. At timed intervals, samples were withdrawn and diluted with THF for SEC and with $\mathrm{CDCl}_{3}$ for $\mathrm{NMR}$ analysis. The reaction mixture was kept under these conditions for the desired time and then it was exposed to air to stop the reaction. The product was precipitated by addition of the reaction mixture to a cold mixture of methanol/water (volume ratio $=1: 1)$ to remove catalyst, and dried under vacuum.

2.4.1.3 Synthesis of PSAN-PtBA-PDVB star copolymer by ARGET ATRP. A clean dry $100 \mathrm{~mL}$ Schlenk flask was charged with $\mathrm{PSAN}_{70}-b-\mathrm{P} t \mathrm{BA}_{40}-\mathrm{Br} \mathrm{MI}\left(M_{\mathrm{n}}=11000 \mathrm{~g} / \mathrm{mol}, 12 \mathrm{~g}, 1.09 \mathrm{mmol}\right), \mathrm{DVB}$ (2.18 mL, $15.2 \mathrm{mmol}), \mathrm{CuBr}_{2}(2.4 \mathrm{mg}, 0.01 \mathrm{mmol})$, TPMA (31.6 mg, $\left.0.11 \mathrm{mmol}\right)$, and anisole (80 mL). The flask was subjected to sonication and then was bubbled with $\mathrm{N}_{2}$ for $30 \mathrm{~min}$. The flask was sealed with a glass stopper and immersed in an oil bath set at $110^{\circ} \mathrm{C}$. A solution of $\mathrm{Sn}(\mathrm{EH})_{2}(0.7 \mathrm{~mL})$ in degassed anisole $(10 \mathrm{~mL})$ was deoxygenated by bubbling $\mathrm{N}_{2}$ for $5-10 \mathrm{~min}$, and $0.1 \mathrm{~mL}$ of the solution 
was added to the reaction flask at different timed intervals $-0,5,10,20,40$, and $50 \mathrm{~h}$ to maintain a low concentration of the $\mathrm{Cu}^{\mathrm{I}} / \mathrm{L}$ complex. At timed intervals, samples were withdrawn via a syringe fitted with stainless steel needle and diluted with THF. The samples were used to measure the monomer conversion and polymer molecular weight by SEC and ${ }^{1} \mathrm{H}$ NMR, respectively. After $20 \mathrm{~h}$ the reaction mixture was exposed to air to stop the polymerization, the unreacted MIs were removed by precipitation of the product in cold methanol, and product was dried under vacuum.

2.4.1.4 Hydrolysis of PSAN-b-PtBA-PDVB star polymers 2.0 g of PSAN- $b$-P $t$ BA-PDVB star polymers were dissolved in $20 \mathrm{~mL}$ DCM. $2.0 \mathrm{~mL}$ of TFA was added slowly to the reaction while the solution was vigorously stirred. The reaction was stirred at room temperature for $48 \mathrm{~h}$. The PSAN- $b$-PAA-PDVB star polymer was obtained as a white solid after precipitation in hexane and removal of solvent and acids under vacuum.

2.4.2 Synthesis of PSAN capped ZnO nanoparticles from star polymer templates. The PSAN- $b$-PAA-PDVB star polymers were used as templates for formation of $\mathrm{ZnO}$ nanoparticles. $100 \mathrm{mg}$ PSAN- $b$-PAA-PDVB star polymer was dissolved in a $10 \mathrm{ml}$ DMF followed by addition of appropriate amounts of $\mathrm{ZnO}$ precursors $\left[\mathrm{Zn}\left(\mathrm{NO}_{3}\right)_{2}, \mathrm{Zn}(\mathrm{OAc})_{2}, \mathrm{Zn}(\mathrm{EH})_{2}\right]$, that were selectively incorporated into the inner PAA blocks. The molar ratio of AA units in the PAA blocks to precursors was set at 1:10 to ensure the complete loading of precursors into the PAA domains. The mixture solutions were stirred at room temperature overnight. Then the mixture was refluxed at $180{ }^{\circ} \mathrm{C}$ for $5 \mathrm{~h}$. A transparent $\mathrm{ZnO}$ nanocomposites DMF dispersion was obtained after removing the remaining solids from the reaction.

2.4.3 Synthesis of one-dimensional $\mathrm{ZnO}$ hybrids. One-dimensional $\mathrm{ZnO}$ hybrids were synthesized following previously reported procedures for synthesis of one-dimensional $\mathrm{TiO}_{2}$ hybrids, with $\mathrm{ZnO}$ precursors.[33]

\subsection{Characterization}

Number average molecular weight $\left(M_{\mathrm{n}}\right)$ and molecular weight distribution $\left(M_{\mathrm{w}} / M_{\mathrm{n}}\right)$ were determined by SEC, conducted with a Waters 515 pump and Waters 2414 different refractometer using PSS columns 
(Styrogel 105,103, $102 \mathrm{~A})$ in THF as an eluent $\left(35^{\circ} \mathrm{C}\right.$, flow rate of $1 \mathrm{~mL}$ min-1). Linear PS and PMMA standards were used for calibration. Conversion was calculated by detecting the decrease of the monomer peak area relative to the peak area of the internal standards. ${ }^{1} \mathrm{H}$ NMR spectroscopy used for polymerization monitoring was performed using a Bruker Advance $300 \mathrm{MHz}$ NMR spectroscope with $\mathrm{CDCl}_{3}$ as a solvent.

Transmission electron microscopy (TEM) was performed using a JEOL 2000 EX electron microscope operated at $200 \mathrm{kV}$. The size of the particles was determined from statistical analysis of the TEM micrographs using ImageJ software. Dynamic light scattering (DLS) using a Malvern Zetasizer Nano ZS was also employed to determine volume-weighted average hydrodynamic radius and distribution to confirm the results obtained from TEM. The particles were suspended in filtered THF or DMF (220 nm PTFE filter) at micro concentrations. To characterize the structure and crystallinity, a Philips X'Pert (Philips Analytical, Netherlands) X-ray diffractometer (XRD) (Cu-Ka radiation) was operated at $45 \mathrm{kV}$ and $40 \mathrm{~mA}$ in grazing incidence mode. The fraction of $\mathrm{ZnO}$ in the nanocomposite was measured by thermogravimetric analysis (TGA), TA Instrument 2950 , and the data was analyzed with TA Universal Analysis. The heating procedure involved 4 steps: 1) samples were placed on a Platinum pan and the temperature jumped to $120^{\circ} \mathrm{C}$ in air atmosphere; 2) the temperature was held at $120^{\circ} \mathrm{C}$ for 10 mins; 3) ramp up at a rate of $20^{\circ} \mathrm{C} / \mathrm{min}$ to $800{ }^{\circ} \mathrm{C}$; 4) hold for 5 mins. The TGA plots were normalized to the total weight of the sample after holding at $120^{\circ} \mathrm{C}$. The grafting densities of hybrid particles were calculated using the following equation:

$$
\sigma_{\mathrm{TGA}}=\frac{\left(1-f_{\mathrm{ZnO}}\right) N_{\mathrm{A}} \rho_{\mathrm{ZnO}} d}{6 f_{\mathrm{ZnO}} \mathrm{M}_{\mathrm{n}}}
$$

where is $f_{\mathrm{ZnO}}$ the $\mathrm{ZnO}$ fraction measured by TGA after exclusion of any residual solvent; $N_{\mathrm{A}}$ is the Avogadro number; $\rho_{\mathrm{ZnO}}$ is the density of zinc oxide NPs; $d$ is the average diameter of $\mathrm{ZnO}$ NPs; $M_{\mathrm{n}}$ is the overall number average molecular weight of polymer brushes. 


\section{Results and Discussion}

\subsection{Synthesis of polymer grafted ZnO NPs by "grafting from" method}

The selection of a suitable coupling agent is important for a successful "grafting-from" method. Herein, 2-BiB was chosen as surface modifier for pristine $\mathrm{ZnO}$ NPs $(\sim 25 \mathrm{~nm}$ in diameter $)$ to introduce active -Br onto the surface of NPs which were then then used as ATRP initiators. ARGET ATRP with low concentration of copper was employed instead of conventional ATRP, owing to the facile setup and simplified catalyst removal process.[48] Two kinds of particle brushes: PMMA- $g$-ZnO and PSAN-g-ZnO NPs, were prepared, as illustrated in Scheme 2. During the polymerization, a large amount of unmodified pristine $\mathrm{ZnO}$ NPs precipitated from the solution. Only ca. $30 \mathrm{wt} \% \mathrm{ZnO}$ NPs were successfully functionalized by $2-\mathrm{BiB}$, due to the poor functionalization of the inert $\mathrm{ZnO}$ surface with ATRP initiators.

Scheme 2. Synthesis of polymer brush grafted $\mathrm{ZnO}$ NPs by "grafting-from" method

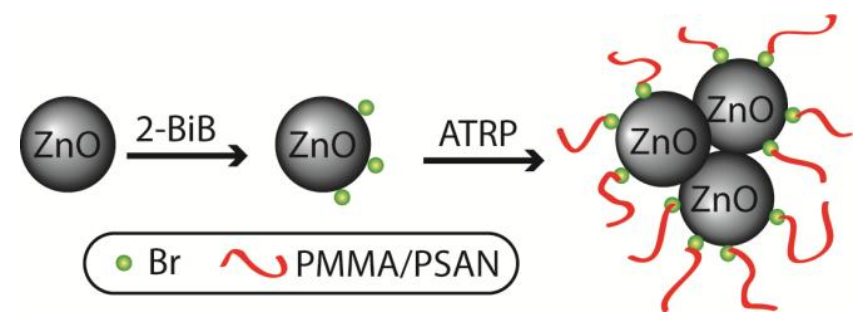

Table 1. PMMA/PSAN-g-ZnO nanoparticles prepared by "grafting-from" method

\begin{tabular}{lcccc}
\hline Sample Identity & $M_{\mathrm{n}}{\text { (polymer brush })^{\mathrm{a}}}$ & Inorganic fraction $^{\mathrm{b}}$ & ${\text { Grafting density }\left(\mathrm{nm}^{-2}\right)^{\mathrm{c}}}$ & ${\text { Average diameter }(\mathrm{nm})^{\mathrm{d}}}^{\text {PMMA-g-ZnO }}$ \\
\hline PSAN-g-ZnO & 169,700 & $34 \%$ & 0.16 & 260 \\
& 98,100 & $44 \%$ & 0.18 & 180
\end{tabular}

$\overline{{ }^{a}}$ Determined by SEC; ${ }^{b}$ determined by TGA; $^{\mathrm{c}}$ calculated from inorganic fraction and polymer molar mass assuming all nanoparticles are spherical; ${ }^{\mathrm{d}}$ z-average hydrodynamic diameter in THF determined by DLS

Both of the hybrid particle products, PMMA- $g-\mathrm{ZnO}$ and PSAN- $g-\mathrm{ZnO}$ NPs, were dispersed in THF to form stable and transparent solutions. However, DLS showed that these $\mathrm{ZnO}$ /polymer nanoparticles 
formed aggregates with diameter of 150-300 nm (PMMA-g-ZnO $260 \mathrm{~nm}$, PSAN-g-ZnO $180 \mathrm{~nm})$ As shown in Table 1, the inorganic content of $\mathrm{ZnO}$ /polymer hybrids are 34 and $44 \mathrm{wt} \%$ for PMMA-g-ZnO and PSAN- $g$-ZnO measured by TGA corresponding to grafting densities of $0.16 \mathrm{~nm}^{-2}$ for PMMA-g-ZnO and $0.18 \mathrm{~nm}^{-2}$ for PSAN- $g-\mathrm{ZnO}$, respectively. Grafting density $>0.15 \mathrm{~nm}^{-2}$ would be sufficient to stabilize these clusters in solutions.[49]

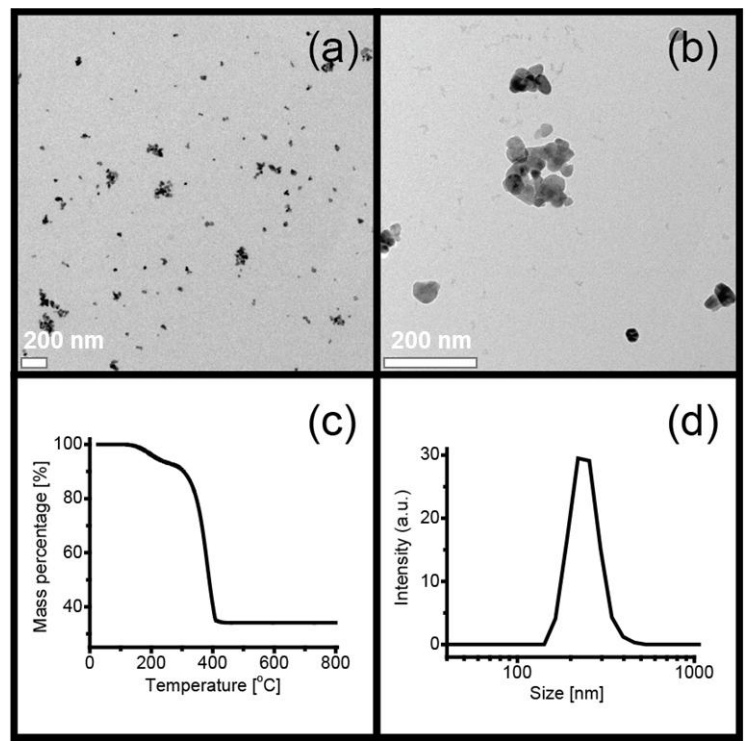

Figure 1. ( $a$ and b) TEM images with different magnifications of the PMMA-g-ZnO NPs, which showed the $\mathrm{ZnO} /$ polymer composites uniform clusters morphology; (c) TGA trace indicating ca. 65 wt\% polymers in this PMMA-g-ZnO composite; (d) hydrodynamic size distribution measured by DLS in THF.

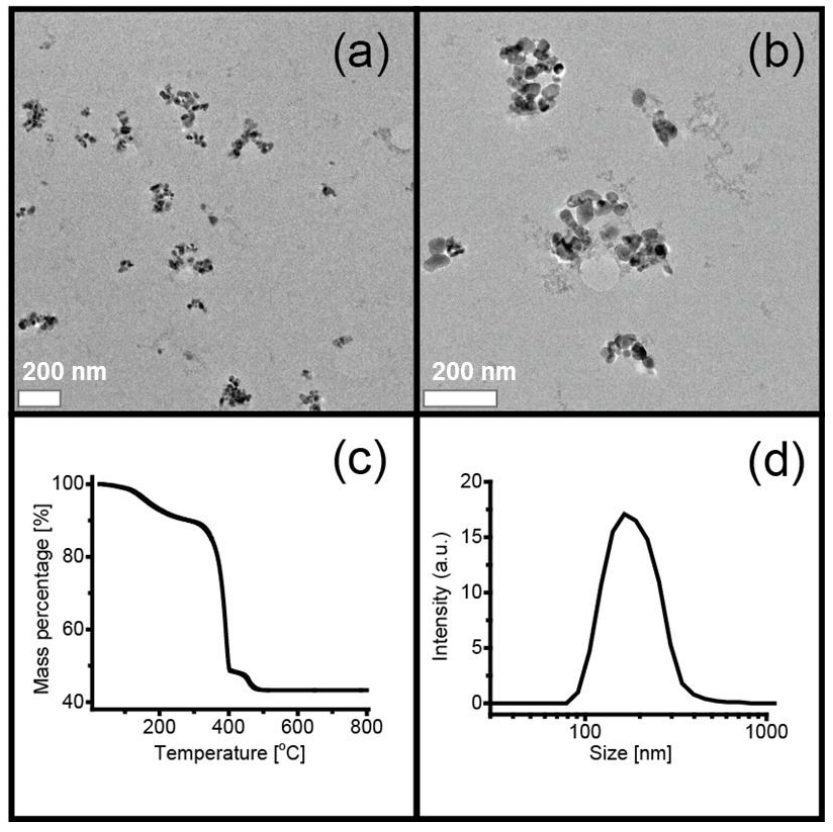


Figure 2. (a and b) TEM images with different magnifications of the PSAN- $g-Z n O$ NPs, which showed the $\mathrm{ZnO} /$ polymer composites uniform clusters morphology; (c) TGA trace indicating ca. $55 \mathrm{wt} \%$ polymers in this PMMA-g-ZnO composite; (d) hydrodynamic size distribution measured by DLS in

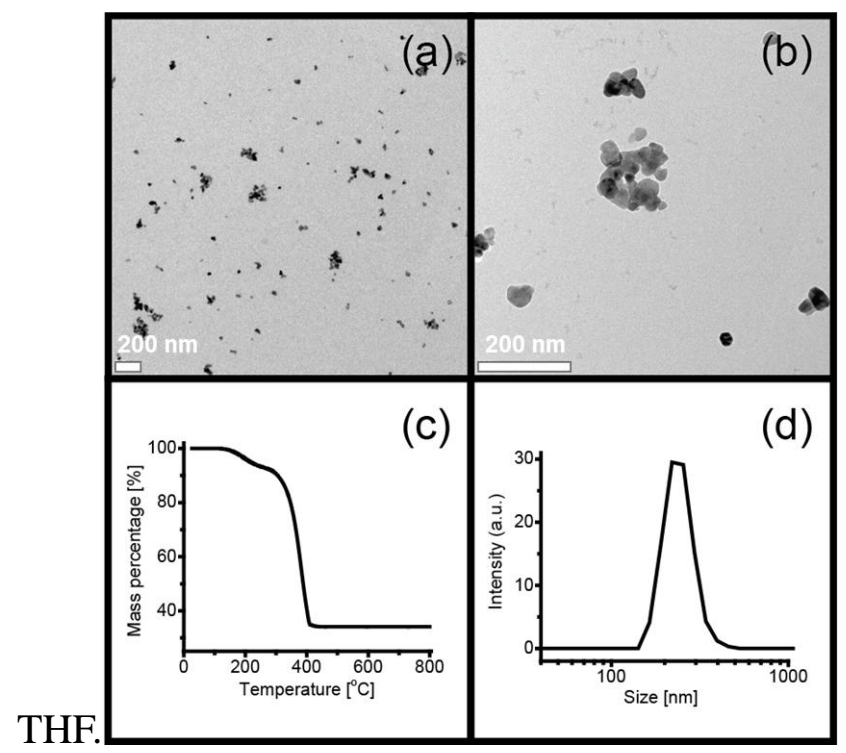

Figure 1 and Figure 2 show that the hybrid particles formed uniform cluster structures with gaps in between, which were distinct from pristine ZnO NPs (Figure S1). The relatively broadly dispersed particle brush samples were observed by DLS. This probably results from the fact that unmodified surface of the NPs tended to agglomerate and form clusters and polymer brushes are grafted from the surface of the agglomerate to form the shell and prevent further aggregation of the NPs.

\subsection{Synthesis of PSAN/PMMA capped ZnO by "grafting-onto" method}

The "grafting-onto" approach is a widely used method to fabricate polymer grafted NPs. The grafting of PMMA or PSAN brushes onto ZnO NPs was accomplished via exploitation of the strong affinity of carboxylates to the $\mathrm{ZnO}$ surfaces (Scheme 3).[50]

Scheme 3. Synthesis of PSAN/PMMA- $b$-PAA capped ZnO by "grafting-onto" method 

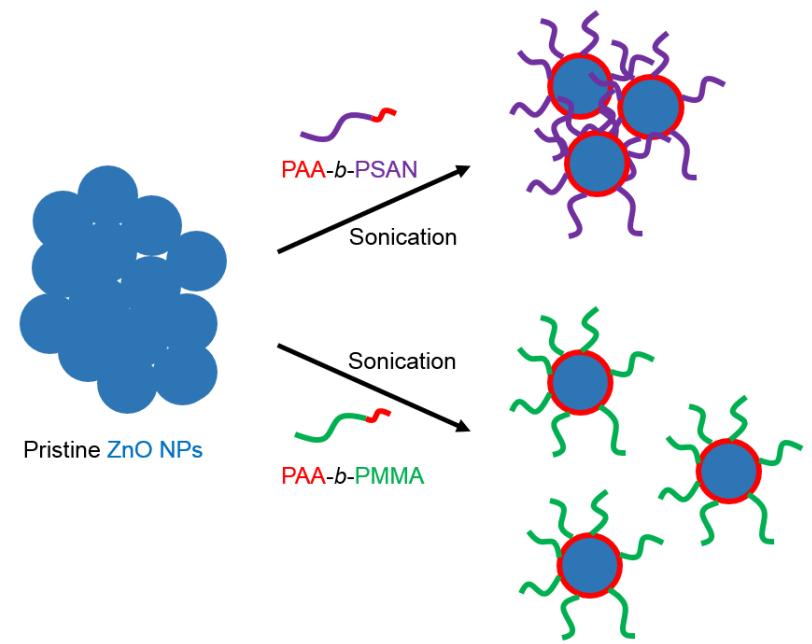

Table 2. PSAN/PMMA capped ZnO by "grafting-onto" method

\begin{tabular}{llccc}
\hline Inorganic filler & Polymer $^{\mathrm{a}}$ & Inorganic fraction $^{\mathrm{b}}$ & ${\text { Grafting density }\left(\mathrm{nm}^{-2}\right)^{\mathrm{c}}}$ & ${\text { Average diameter }(\mathrm{nm})^{\mathrm{d}}}^{\mathrm{N}}$ \\
$\mathrm{ZnO}$ & $\mathrm{PAA}_{12}-b-\mathrm{PSAN}_{62}$ & $93 \%$ & 0.11 & 160 \\
& $\mathrm{PAA}_{12}-b$-PMMA $_{59}$ & $92 \%$ & 0.13 & 122 \\
\hline
\end{tabular}

${ }^{a}$ Determined by SEC before hydrolysis; ${ }^{b}$ determined by TGA; $^{c}$ calculated from inorganic fraction and polymer molar mass assuming all nanoparticles are spherical; ${ }^{\mathrm{d}} \mathrm{z}$-average hydrodynamic diameter in THF determined by DLS; ${ }^{\mathrm{e}}$ supplied by US Research Nanomaterials as dry powders, diameter $18 \mathrm{~nm}$ as claimed by the supplier.

As shown in Table 2, two diblock copolymers each with a short poly(acrylic acid) (PAA) block were synthesized via ATRP and hydrolysis of the PtBA segments. In order to synthesize PAA- $b$-PSAN, and prevent distinction of reactivity of $\mathrm{S}-\mathrm{Br}$ and $\mathrm{AN}-\mathrm{Br}$ chain ends, [51] a short $\mathrm{P} t \mathrm{BA}$ block was initially synthesized via initiator for continuous activator regeneration (ICAR) ATRP followed by chain extension with an azeotropic mixture of $\mathrm{S}$ and AN.[52] In the case of the PAA- $b$-PMMA, a PMMA-Br macroinitiator was synthesized first to avoid inefficient initiation from acrylate chain end.[53] The tert-butyl group was hydrolyzed with 10 vol\% TFA in DCM.

In both cases, the NPs were first dispersed in THF with a sonicating probe to sufficiently expose the surface of the particles to the carboxylic acids. After that, the reaction mixture was sonicated in a bath at $50{ }^{\circ} \mathrm{C}$ for $48 \mathrm{~h}$. No sediment was observed in the resulting dispersion. However, the two samples 
displayed distinctly different results. A low level of aggregation of PSAN-g-ZnO NPs, of ca. $150 \mathrm{~nm}$, was observed by both DLS and TEM (Figure 3 and Figure 4). In contrast, PMMA-g-ZnO displayed an insignificant degree of aggregation. The difference in polarity between PSAN and PMMA may contribute to such difference.
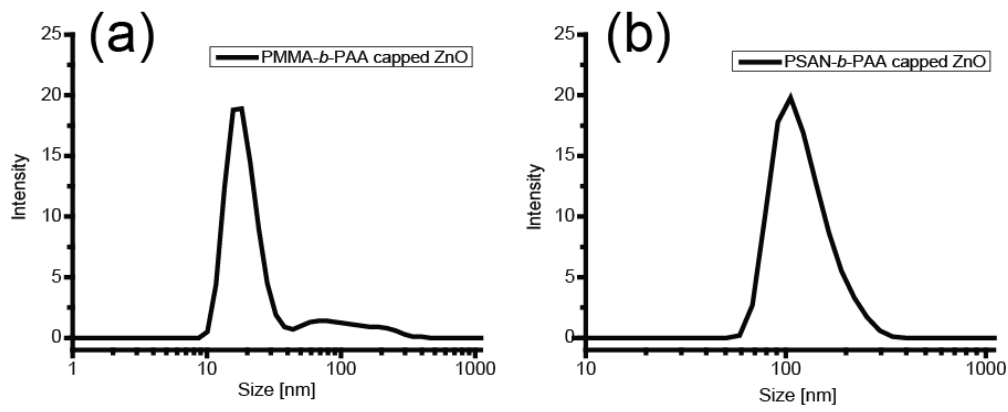

Figure 3. DLS hydrodynamic size distributions. $1 \mathrm{mg} / \mathrm{mL}$ dispersion in THF: (a) PMMA- $b$-PAA capped $\mathrm{ZnO}$ NPs showing $\left\langle D_{\mathrm{h}}\right\rangle=122 \mathrm{~nm}$ with narrow size distribution peak at ca. $20 \mathrm{~nm}$ and slight aggregation signal at $c a$. 50-300 nm, (b) PSAN-b-PAA capped ZnO NPs showing $\left\langle D_{\mathrm{h}}\right\rangle=160 \mathrm{~nm}$ with size distribution ranging from 60-300 nm.

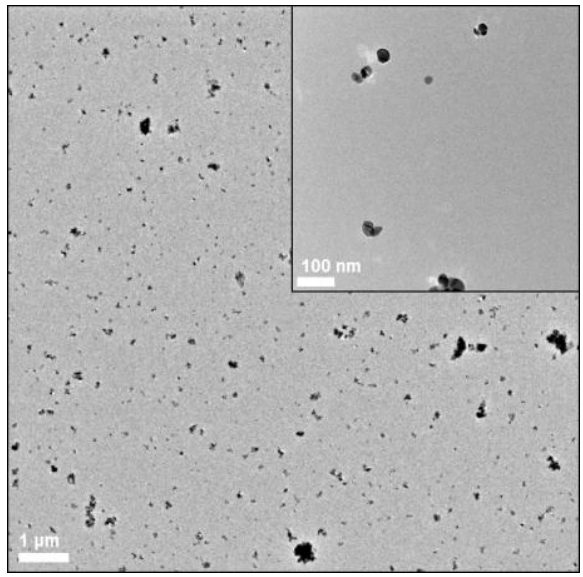

Figure 4. TEM images of PMMA- $g$-ZnO NPs via "grafting-onto" approach. Negligible aggregation was observed. Inset: magnified TEM image.

\subsection{Synthesis of PSAN capped $\mathrm{ZnO}$ by "star template" method}

As illustrated in Scheme 4, an "arm-first" method was applied to the synthesis of PSAN- $b$-PAA-PDVB star polymers, which can be used as a soft template for the fabrication of $\mathrm{ZnO}$ hybrid nanomaterials.[54-56] ARGET ATRP was used for both the preparation of the multifunctional macroinitiator (MI) and linkage of the arms by chain extension with DVB. Initially, a highly 
functionalized, PSAN-Br macroinitiator, with $M_{\mathrm{n}}=5,800$ and $M_{\mathrm{w}} / M_{\mathrm{n}}=1.12$ was synthesized via ARGET ATRP. The macroinitiator was chain extended with a second monomer, $t \mathrm{BA}$, to form PSAN- $b-\mathrm{P} t \mathrm{BA}-\mathrm{Br}$ diblock copolymer. During the chain extension polymerization, the SEC traces of the product shifted to higher molecular weight, indicating the formation of diblock copolymers (Figure S4). Finally, DVB was employed to simultaneously chain extend and cross-link the PSAN- $b$-P $t$ BA-Br MIs to form the PSAN- $b$-PtBA-PDVB star copolymer. A timed-feeding method was used in the reaction to control the concentration of activator in the system forming PSAN- $b$-P $t$ BA-PDVB star block polymers $\left(M_{\mathrm{n}}=67,800, M_{\mathrm{w}} / M_{\mathrm{n}}=1.88\right)$. After deprotection of the PtBA segments with TFA, the PSAN- $b$-PAA-PDVB star polymers were obtained. The SEC traces in Figure S4 showing decreasing signal corresponding to the unreacted MIs and increasing peak at higher molecular weight region suggests the formation of star polymers.

$\mathrm{Zn}(\mathrm{EH})_{2}$ is an appropriate precursor for in situ synthesis of $\mathrm{ZnO}$ particles because it is cost-effective, air-stable, and non-toxic.[57] $\mathrm{Zn}(\mathrm{EH})_{2}$ precursors were loaded into PSAN- $b$-PAA-PDVB star polymer templates. The hydrophilic PAA blocked inside the core impart preferential incorporation of $\mathrm{Zn}(\mathrm{EH})_{2}$ into the interior space of the star via a strong coordination bonding between the metal moiety and the carboxylic groups of PAA segments whereas the outer PSAN corona did not complex with $\mathrm{Zn}(\mathrm{EH})_{2}$ and remained unloaded. Excess $\mathrm{Zn}(\mathrm{EH})_{2}$ was loaded into the star template solutions to ensure saturation of PAA cores with precursors. The hybrid nanomaterials were then refluxed in $\mathrm{DMF}$ at $180{ }^{\circ} \mathrm{C}$ for complete hydrolysis of $\mathrm{Zn}(\mathrm{EH})_{2}$ to form $\mathrm{ZnO}$ NPs within star templates. The shell of the nanoparticles was intimately and permanently connected with hydrophobic PSAN blocks. PSAN coronas prevented intermolecular cross-linking during hybrid formation and solubilize the ZnO hybrid NPs in organic solvents (e.g. toluene, THF, chloroform, DCM, DMF, etc.) to form stable and transparent solutions. Unbound $\mathrm{ZnO}$ NPs formed from excess precursors in the solution were removed by centrifugation. A summary of the synthetic route is illustrated in Scheme 4.

Scheme 4. Hybrid $\mathrm{ZnO}$ nanoparticles formation using PSAN- $b$-PAA-PDVB star copolymer templates. 


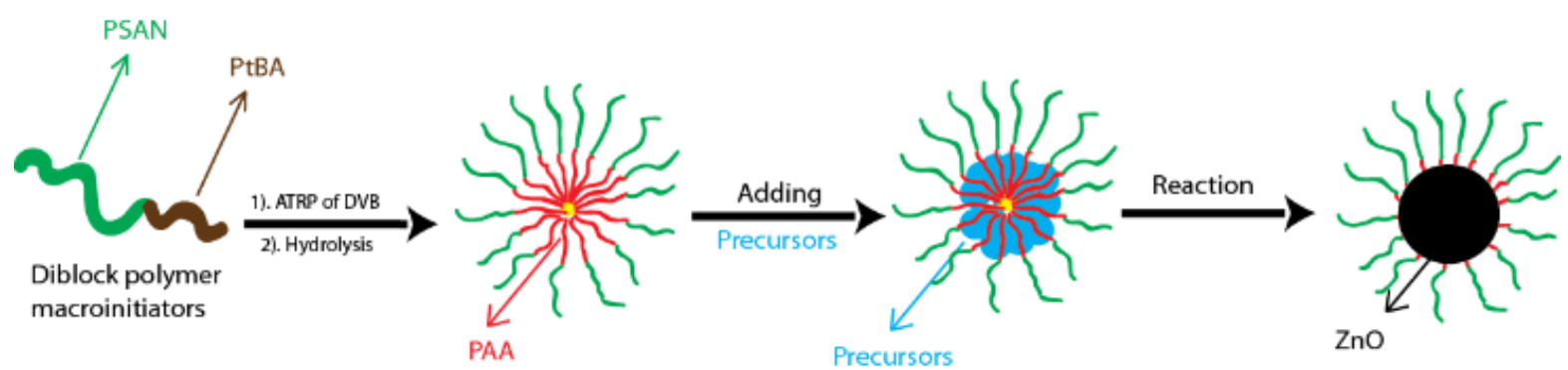

After infiltration and thermal hydrolysis of $\mathrm{Zn}(\mathrm{EH})_{2}$ within the star templates, the chains within PAA compartment were stretched. The average diameter of the star increased to $25 \pm 2 \mathrm{~nm}$ compared to the $18 \pm 2 \mathrm{~nm}$ of the pristine unloaded star templates as measured by DLS (

Figure 5e). ZnO NPs were homogeneously dispersed in the polymer with no free $\mathrm{ZnO}$ NPs in the background as assessed by TEM (Figure 5a-c). The ZnO NPs had good uniformity with diameter of 3-5 nm. TEM images of inorganic particles formed from the precipitates of free ZnO NPs in the solution show aggregation of nanostructures indicating that the presence of hydrophobic PSAN blocks was crucial to ensure the miscibility of NPs with the host matrix by preventing aggregation and encouraging dispersibility.

The XRD patterns (Figure S5 and S6) confirm the formation of crystalline ZnO. The XRD patterns consist of diffraction peaks corresponding to the reflections from (100), (002), (101), (102) and (110) planes of a wurtzite $\mathrm{ZnO}$ crystal (JCPDS-36-1451). Peak broadening suggests that the individual crystalline NPs were quite small. TGA determined the weight fraction of $\mathrm{ZnO}$ in the star templates with 40 repeating units of PAA to be $11.7 \mathrm{wt} \%$.

Star templates with various degrees of polymerization (DP $=40,70$, and 90, respectively) were used to study the effect of star template size on ZnO NP formation. Retaining an equal DP of PSAN on the star template shell facilitated better comparison of the amount of inorganic loading in the PAA core, as shown in samples 1, 2 and 3 for the ZnO NPs. in Table 3. TGA determined the weight of $\mathrm{ZnO}$ in the star templates increased from 11.7 wt $\%$ with DP 40 of PAA to 27.5 wt $\%$ with DP 90 of PAA. These data suggest that PAA with relatively high DP increased chain mobility, loaded more $\mathrm{Zn}(\mathrm{EH})_{2}$ precursors into the core, and subsequently increased the loading capacity. Conversely, the diameter of 
ZnO NPs $\left(D_{Z n O-N P} \sim 3-5 \mathrm{~nm}\right)$ was essentially independent of the DP of PAA DP in the core of star templates. A possible reason for the independence of the $\mathrm{ZnO}$ NP size on the PAA block length may be that the longer PAA block results in a lower PAA block density within the compartment partially occupied by PAA chains, thus allowing a larger degree of collapse of PAA blocks.

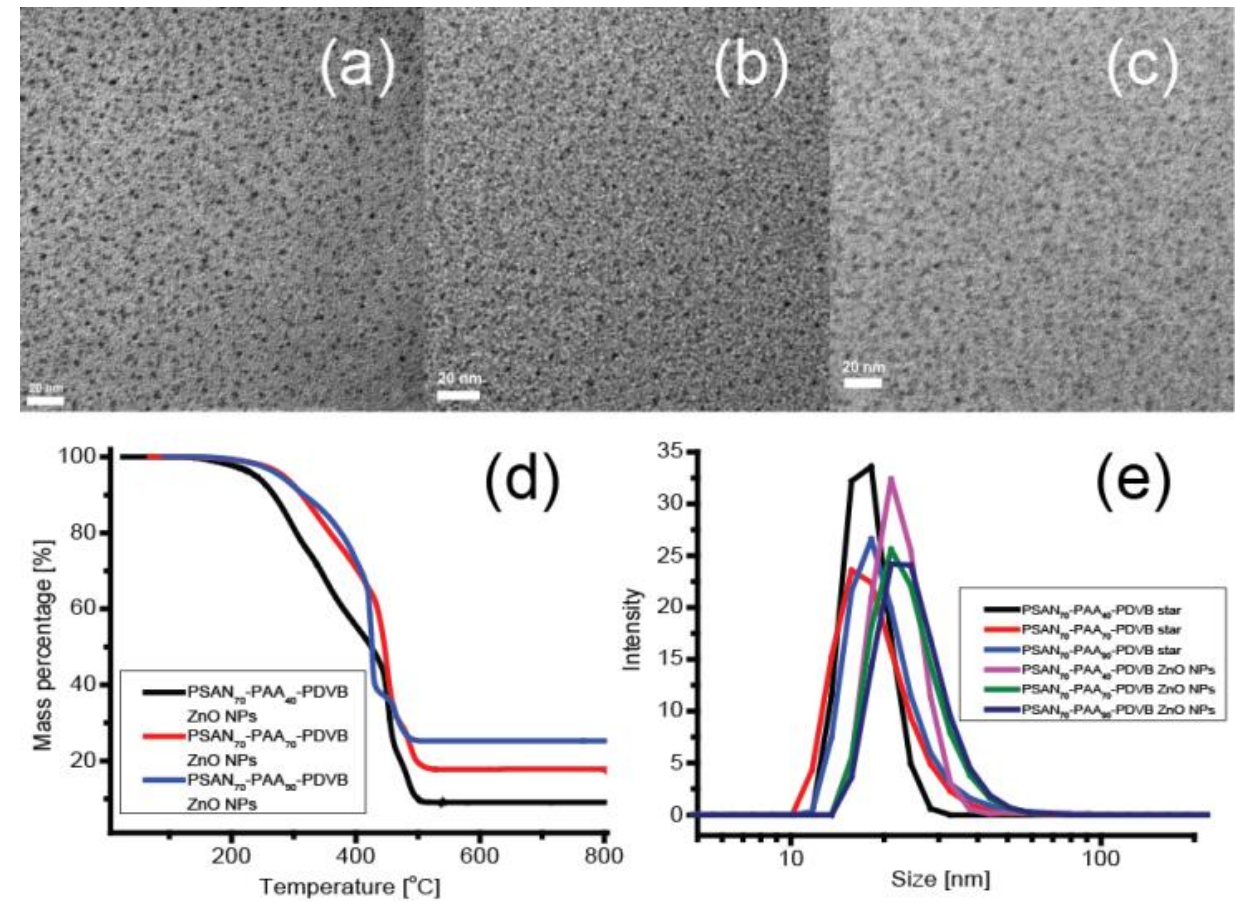

Figure 5. (a, b, and c) TEM images of PSAN capped ZnO NPs synthesized by different star polymer templates and $\mathrm{Zn}(\mathrm{EH})_{2}$ precursors: (a) PSAN $_{70}-b$-PAA $40-\mathrm{PDVB}$ star copolymer, (b) PSAN $_{70}-b$-PAA $70-\mathrm{PDVB}$ star polymer, (c) $\mathrm{PSAN}_{70}-b$-PAA $90-\mathrm{PDVB}$ star polymer. All TEM images indicated homogeneous dispersion of ZnO NP. (d) TGA traces of PSAN- $b$-PAA-PDVB ZnO NP showing increasing organic content with DP of the PAA blocks; (e) DLS hydrodynamic size distributions of PSAN- $b$-PAA-PDVB ZnO NPs in DMF showing the increase of size with DP of the PAA blocks and after loading.

Table 3. Results of PSAN-b-PAA-PDVB star copolymer templates the ZnO NPs.

\begin{tabular}{|c|c|c|c|c|c|c|c|c|c|}
\hline Entry & Composition & $\begin{array}{l}M_{\mathrm{n}} \\
\text { PSAN }^{\mathrm{a}}\end{array}$ & $M_{\mathrm{n}, \mathrm{PAA}}{ }^{\mathrm{a}}$ & $M_{\mathrm{n}, \mathrm{star}}{ }^{\mathrm{a}}$ & $M_{\mathrm{w}} / M_{\mathrm{n}}^{\mathrm{a}}$ & $\begin{array}{l}D_{\mathrm{h}, \mathrm{star}}{ }^{\mathrm{b}} \\
(\mathbf{n m})\end{array}$ & $\begin{array}{l}D_{\mathrm{h}, \mathrm{star}+\mathrm{ZnO}}{ }^{\mathrm{c}} \\
(\mathrm{nm})\end{array}$ & $\begin{array}{l}\mathrm{ZnO} \\
\text { Fractio } \\
\mathbf{n}^{\mathbf{d}}\end{array}$ & $\begin{array}{l}\text { Diameter of } \\
\mathrm{ZnO} \quad \mathrm{NP} \\
(\mathrm{nm})^{\mathrm{e}}\end{array}$ \\
\hline 1 & $\begin{array}{l}\mathrm{PSAN}_{70^{-}}-b-\mathrm{PA} \\
\mathrm{A}_{40}-\mathrm{PDVB}\end{array}$ & 5,800 & 11,000 & 67,800 & 1.88 & $16 \pm 1.8$ & $20 \pm 2.2$ & $11.7 \%$ & $3-5$ \\
\hline 2 & $\mathrm{PSAN}_{70^{-}} b-\mathrm{PA}$ & 5,300 & 13,000 & 60,600 & 3.0 & $18 \pm 2.0$ & $22 \pm 1.8$ & $17.2 \%$ & $3-5$ \\
\hline
\end{tabular}




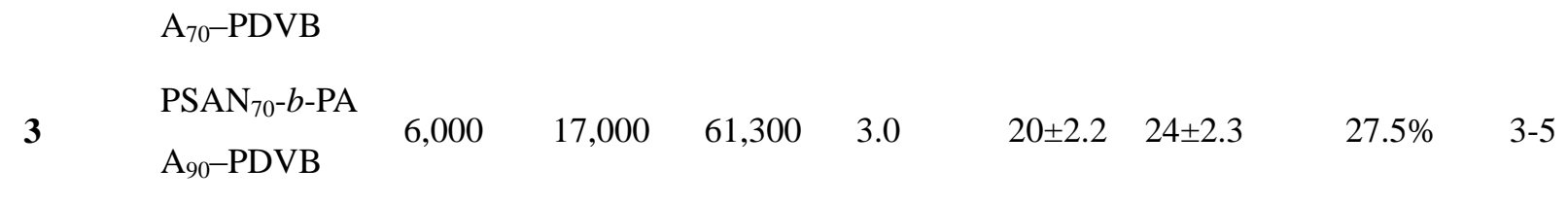

a) Molecular weights and molecular weight distributions were measured by THF SEC using linear PS standards as calibration; b) $D_{\mathrm{h}}$ of PSAN- $b$-PAA-PDVB star polymer in DMF measured by DLS; c) $D_{\mathrm{h}}$ of PSAN-PAA-PDVB star polymer loading with ZnO NPs in DMF measured by DLS; d) the amount of inorganic ZnO NPs of hybrid materials measured by TGA; e) the diameter of ZnO NPs measured by TEM.

In order to study the effect of the $\mathrm{Zn}$ precursors on the $\mathrm{ZnO}$ NPs, three different zinc compounds, $\mathrm{Zn}(\mathrm{EH})_{2}, \mathrm{Zn}\left(\mathrm{NO}_{3}\right)_{2}, \mathrm{Zn}(\mathrm{OAc})_{2}$, were used as $\mathrm{ZnO}$ precursors and formed complexes within PSAN $_{70}-b$-PAA 40 -PDVB templates. The morphology, size and crystallinity of $\mathrm{ZnO}$ crystals was assessed by TEM (Figure 6). The diameter of ZnO NPs was observed to be approximately 8, 4-5 and 3 $\mathrm{nm}$ for the precursors $\mathrm{Zn}\left(\mathrm{NO}_{3}\right)_{2}, \mathrm{Zn}(\mathrm{EH})_{2}$ and $\mathrm{Zn}(\mathrm{OAc})_{2}$, respectively. $\mathrm{ZnO} \mathrm{NPs}$ from $\mathrm{Zn}\left(\mathrm{NO}_{3}\right)_{2}$ had a higher contrast than that of $\mathrm{Zn}(\mathrm{EH})_{2}$ and $\mathrm{Zn}(\mathrm{OAc})_{2}$, but the yield of the NPs was not as high. It can be seen from TEM images (Figure S7) that there were some free ZnO NPs aggregated in the background. $\mathrm{KOH}$ is a strong base and can efficiently react with $\mathrm{Zn}\left(\mathrm{NO}_{3}\right)_{2}$ to form $\mathrm{Zn}(\mathrm{OH})_{2}$. The decomposition of $\mathrm{Zn}(\mathrm{OH})_{2}$ is much faster than that of an organic acid based zinc, such as $\mathrm{Zn}(\mathrm{EH})_{2}$ and $\mathrm{Zn}(\mathrm{OAc})_{2}$. The base $(\mathrm{KOH})$ more readily forms a complex with $\mathrm{Zn}^{2+}$ than the PAA, resulting in the formation of $\mathrm{Zn}(\mathrm{OH})_{2}$ in the solution. The $\mathrm{Zn}(\mathrm{OH})_{2}$ in solution formed free $\mathrm{ZnO}$ NPs, which is the reason for the low yield of $\mathrm{ZnO} \mathrm{NPs}$.

$\mathrm{ZnO}$ templates could be directly obtained from $\mathrm{Zn}(\mathrm{EH})_{2}$ and $\mathrm{Zn}(\mathrm{OAc})_{2}$ after reflux in DMF due to the metal-oxygen bond in the organometallic precursors. These ZnO NPs dispersed well in good solvents and selected polymers with good uniformity. The diameter of $\mathrm{ZnO}$ NPs from $\mathrm{Zn}(\mathrm{OAc})_{2}$ was smaller than that of $\mathrm{Zn}(\mathrm{EH})_{2}$. All samples were identified by XRD as wurtzite $\mathrm{ZnO}$ crystals. These results demonstrated that the size of $\mathrm{ZnO}$ NPs was dependent on the composition of the zinc precursors. 


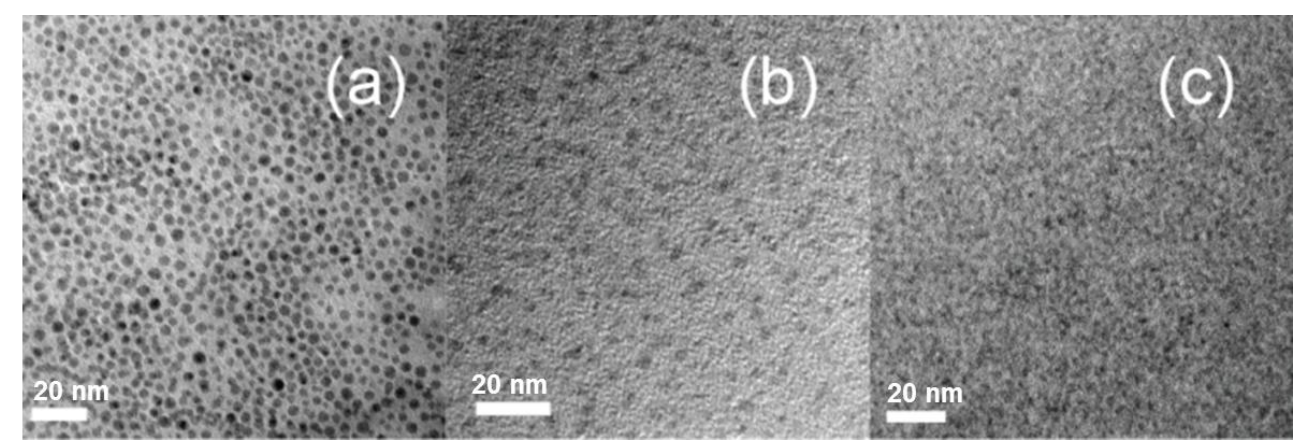

Figure 6. TEM images of PSAN capped ZnO synthesized by PSAN $70-b-\mathrm{PAA}_{40}-\mathrm{PDVB}$ star copolymer template and different $\mathrm{ZnO}$ precursors: (a) $\mathrm{Zn}\left(\mathrm{NO}_{3}\right)_{2}$ and $\mathrm{NaOH}$, (b) $\mathrm{Zn}(\mathrm{EH})_{2}$, (c) $\mathrm{Zn}(\mathrm{OAc})_{2}$. All three samples displayed good dispersibility.
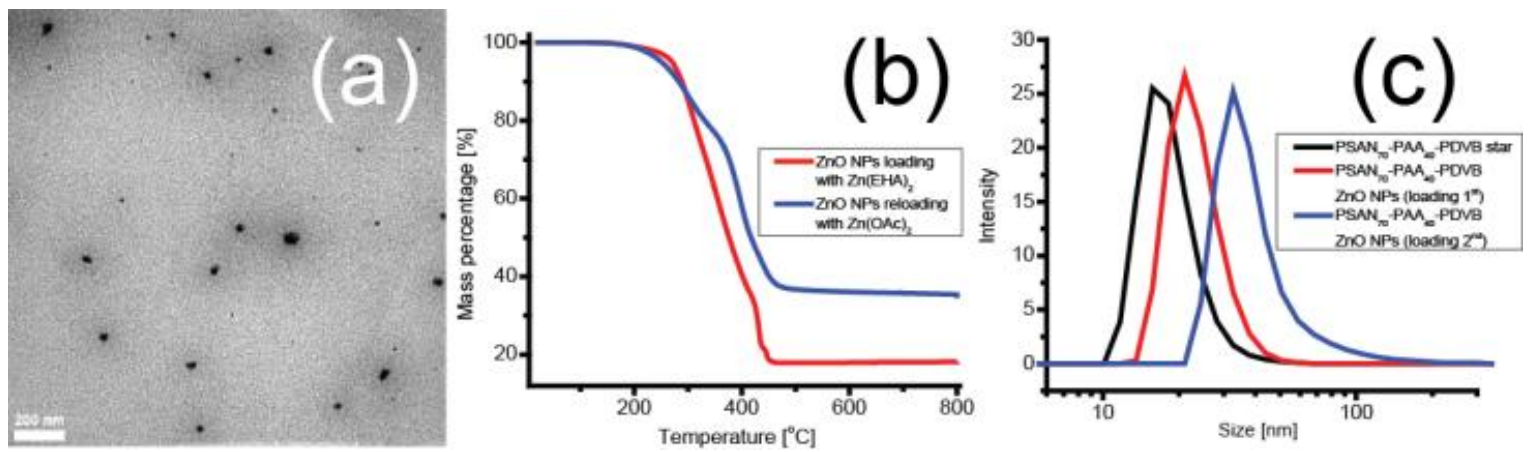

Figure 7. (a) TEM image of PSAN capped ZnO NPs synthesized by reloading presynthesized PSAN capped $\mathrm{ZnO}$ with $\mathrm{Zn}(\mathrm{OAc})_{2}$ precursor; (b) TGA traces of PSAN capped $\mathrm{ZnO}$ Ns showing increased inorganic content after $2^{\text {nd }}$ loading; (c) DLS hydrodynamic sizes of PSAN capped ZnO nanoparticles in DMF solutions growing with the loading of $\mathrm{ZnO}$.

Dispersions were prepared by dispersing purified hybrid $\mathrm{ZnO}$ NPs in DMF and adding $\mathrm{Zn}(\mathrm{EH})_{2}$ precursors in excess. The hybrid nanomaterials in DMF were then refluxed at $180{ }^{\circ} \mathrm{C}$ to ensure complete hydrolysis of the incorporated $\mathrm{Zn}(\mathrm{EH})_{2}$ precursors. TEM showed the size of $\mathrm{ZnO}$ NPs increase greatly from $5 \mathrm{~nm}$ to $20 \mathrm{~nm}$ after sequential loading. DLS also showed $D_{\mathrm{h}}$ of star copolymers containing $\mathrm{ZnO}$ NPs increase from $20 \mathrm{~nm}$ to $45 \mathrm{~nm}$ with increase of inorganic content from 11.7 to $30 \mathrm{wt} \%$ measured by TGA, Figure 7a. These results demonstrated that the initially encapsulated ZnO NPs could be used as seeds to grow larger NPs through sequential loading of $\mathrm{Zn}(\mathrm{EH})_{2}$ precursors.

$\mathrm{ZnO}$ nanoparticles were also prepared using brush-like templates $\left(\mathrm{PBiBEM}_{372}-g-\left(\mathrm{PAA}_{47}-b-\mathrm{PS}_{92}\right)\right)$ with poly(acrylic acid)-block-polystyrene (PAA-b-PS) side chains, as previously reported [33].

Scheme 5. Hybrid $\mathrm{ZnO}$ nanoparticles formation using PAA-PS brush-like templates 


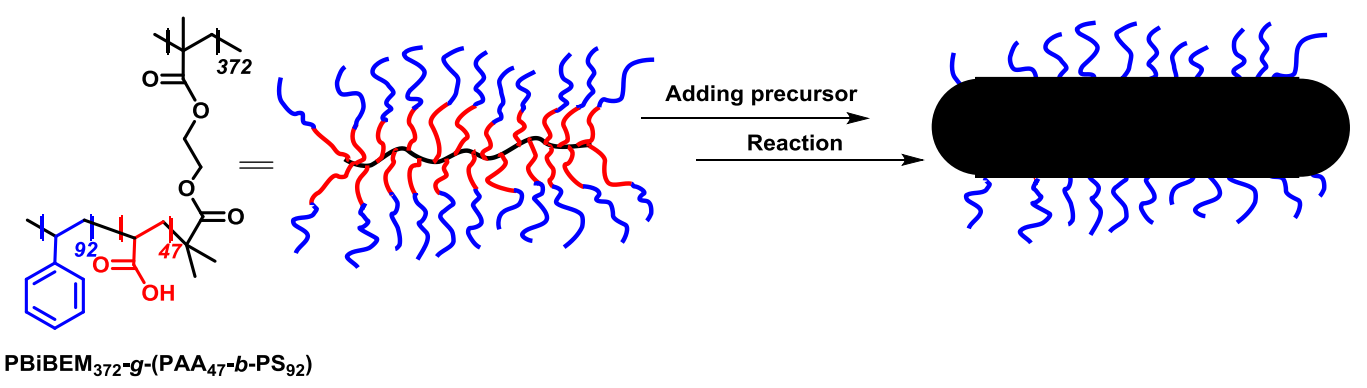

Anisotropic nanoparticles with a worm-like structure were observed in the TEM images (Figure 8). The statistical analysis of TEM images indicates that the number-average lengths of the worm-like nano-objects $75 \mathrm{~nm}$ with dispersity $\left(\mathrm{L}_{\mathrm{w}} / \mathrm{L}_{\mathrm{n}}\right)=1.08$. The length of each repeat unit in backbone is calculated to be $0.16 \mathrm{~nm}$, indicating the backbone of brush-like template does not adapt fully extended conformation. Effective control over the width of nanoparticles is supported by the dispersity of width as low as 1.04 .

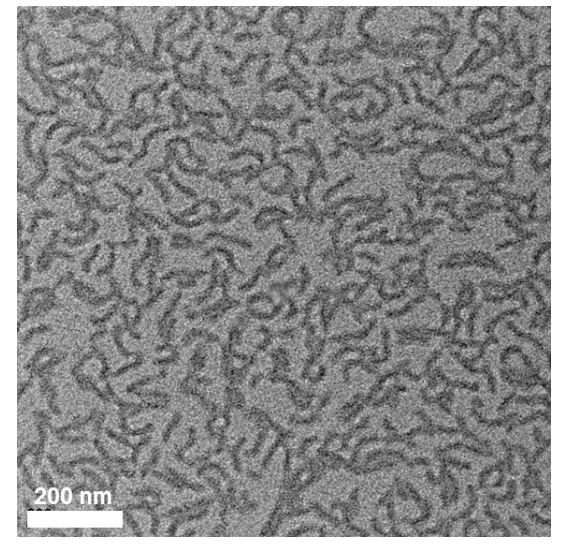

Figure 8. TEM images of $\mathrm{ZnO}$ nanoparticles prepared from brush-like templates.

Table 4. TEM characterization of the length $\left(L_{n}\right)$ and core diameter $\left(W_{n}\right)$ of zinc oxide hybrid nanoparticles prepared from brush template.

\begin{tabular}{ccccc}
\hline Template ID & $L_{n}(\mathbf{n m})$ & $\boldsymbol{L}_{w} / \boldsymbol{L}_{n}{ }^{\mathrm{a}}$ & $W_{n}(\mathbf{n m})$ & $W_{w} / W_{n}{ }^{\mathrm{a}}$ \\
\hline $\mathrm{L}_{372} \mathrm{~A}_{47} \mathrm{~S}_{92}$ & $75 \pm 1$ & 1.08 & $15.0 \pm 0.3$ & 1.04 \\
\hline
\end{tabular}

${ }^{a}$ Dispersity index of zinc oxide nanoparticles length or width obtained from TEM images.

\section{Conclusions}


$\mathrm{ZnO}$ /polymer hybrid materials with different sizes were successfully synthesized by three different methods: "grafting-from", "grafting-onto" and "grafted-copolymer template". Both SI-ATRP (using 2-BiB to introduce ATRP initiators onto the surfaces) as well as the "grafting-onto" method (by surface-adsorption of PMMA/PSAN-b-PAA diblock polymers) were successfully used to tether PMMA to commercial $\mathrm{ZnO}$ nanoparticles and to enable their dispersion in organic solvents. However, gradual aggregation of particles in solution confirms a low grafting density that limits the stabilization of particles. In contrast, polymer tethered $\mathrm{ZnO}$ nanoparticles are synthesized in a one-step procedure using PSAN- $b$-PAA-PDVB star polymers and PAA- $b$-PS copolymer brushes as template for particle synthesis. $\mathrm{Zn}\left(\mathrm{NO}_{3}\right)_{2}, \mathrm{Zn}(\mathrm{OAc})_{2}, \mathrm{Zn}(\mathrm{EH})_{2}$ were studied as precursors of $\mathrm{ZnO}$ formed within the PAA-core of the star copolymers, among which $\mathrm{Zn}(\mathrm{EH})_{2}$ turned out to be the best choice taking cost, yield, and quality into account. Excellent particle size uniformity was obtained using the star template method and dispersions were stable without indication of aggregation. Given the wide range of chemical compositions of possible star-polymer template compositions the technique could conceivably be used to tailor the compatibility of $\mathrm{ZnO}$ particles to a wide range of organic media. The development of convenient methods for the synthesis of $\mathrm{ZnO}$-polymer hybrid materials with controlled size and inorganic composition could therefore broaden the future applications of $\mathrm{ZnO}$ based materials, including drug delivery, photo catalyst, and electronic sensors.

\section{Corresponding Author}

* E-mail: cbetting@andrew.cmu.edu (C.J.B.)

* E-mail: bockstaller@cmu.edu (M.R.B.).

* E-mail: km3b@andrew.cmu.edu (K.M.).

\section{Author Contributions}

The manuscript was written through contributions of all authors. All authors have given approval to the final version of the manuscript. 


\section{ACKNOWLEDGMENT}

Funding provided by the following organizations: the National Science Foundation (DMR 1501324, DMR 1436219); DOE (EE 0006702); the National Science Center (2014/14/A/ST5/0020); the Natural Science Foundation of China (NSFC51273022).

\section{REFERENCES}

[1] H. Althues, J. Henle, S. Kaskel, Functional inorganic nanofillers for transparent polymers, Chem. Soc. Rev. 36(9) (2007) 1454-1465.

[2] A. Kołodziejczak-Radzimska, T. Jesionowski, Zinc oxide-from synthesis to application: a review, Materials 7(4) (2014) 2833-2881.

[3] S. Li, M.M. Lin, M.S. Toprak, D.K. Kim, M. Muhammed, Nanocomposites of polymer and inorganic nanoparticles for optical and magnetic applications, Nano Rev. 1 (2010).

[4] R.R. Dickerson, S. Kondragunta, G. Stenchikov, K.L. Civerolo, B.G. Doddridge, B.N. Holben, The Impact of Aerosols on Solar Ultraviolet Radiation and Photochemical Smog, Science 278(5339) (1997) 827-830.

[5] T. Masui, M. Yamamoto, T. Sakata, H. Mori, G.-y. Adachi, Synthesis of BN-coated CeO2 fine powder as a new UV blocking material, J. Mater. Chem. 10(2) (2000) 353-357.

[6] I. Mora-Seró, J. Bisquert, F. Fabregat-Santiago, G. Garcia-Belmonte, G. Zoppi, K. Durose, Y. Proskuryakov, I. Oja, A. Belaidi, T. Dittrich, R. Tena-Zaera, A. Katty, C. Lévy-Clément, V. Barrioz, S.J.C. Irvine, Implications of the Negative Capacitance Observed at Forward Bias in Nanocomposite and Polycrystalline Solar Cells, Nano Lett. 6(4) (2006) 640-650.

[7] S. Ojha, A. Dang, C.M. Hui, C. Mahoney, K. Matyjaszewski, M.R. Bockstaller, Strategies for the synthesis of thermoplastic polymer nanocomposite materials with high inorganic filling fraction, Langmuir 29(28) (2013) 8989-8996.

[8] A. Dang, S. Ojha, C.M. Hui, C. Mahoney, K. Matyjaszewski, M.R. Bockstaller, High-Transparency Polymer Nanocomposites Enabled by Polymer-Graft Modification of Particle Fillers, Langmuir 3o(48) (2014) 14434-14442.

[9] J. Yan, T. Kristufek, M. Schmitt, Z. Wang, G. Xie, A. Dang, C.M. Hui, J. Pietrasik, M.R. Bockstaller, K. Matyjaszewski, Matrix-free Particle Brush System with Bimodal Molecular Weight Distribution Prepared by SI-ATRP, Macromolecules (2015).

[1o] C.M. Hui, J. Pietrasik, M. Schmitt, C. Mahoney, J. Choi, M.R. Bockstaller, K. Matyjaszewski, Surface-Initiated Polymerization as an Enabling Tool for Multifunctional (Nano-)Engineered Hybrid Materials, Chem. Mater. 26(1) (2013) 745-762.

[11] A. Khabibullin, E. Mastan, K. Matyjaszewski, S. Zhu, Surface-Initiated Atom Transfer Radical Polymerization, Adv. Polym. Sci. 270 (2016) 29-76.

[12] R. Barbey, L. Lavanant, D. Paripovic, N. Schüwer, C. Sugnaux, S. Tugulu, H.-A. Klok, Polymer brushes via surface-initiated controlled radical polymerization: synthesis, characterization, properties, and applications, Chem. Rev. 109(11) (2009) 5437-5527.

[13] M.N. Tchoul, M. Dalton, L.-S. Tan, H. Dong, C.M. Hui, K. Matyjaszewski, R.A. Vaia, Enhancing the fraction of grafted polystyrene on silica hybrid nanoparticles, Polymer 53(1) (2012) 79-86.

[14] R. Barbey, L. Lavanant, D. Paripovic, N. Schüwer, C. Sugnaux, S. Tugulu, H.-A. Klok, Polymer Brushes via Surface-Initiated Controlled Radical Polymerization: Synthesis, Characterization, Properties, and Applications, Chem. Rev. 109(11) (2009) 5437-5527.

[15] K. Matyjaszewski, N.V. Tsarevsky, Nanostructured functional materials prepared by atom transfer radical polymerization, Nat. Chem. 1(4) (2009) 276-288.

[16] Y. Tsujii, K. Ohno, S. Yamamoto, A. Goto, T. Fukuda, Structure and Properties of High-Density Polymer Brushes Prepared by Surface-Initiated Living Radical Polymerization, Adv. Polym. Sci. 197 (2006) 1-45.

[17] L.A. García Rodenas, M.A. Blesa, P.J. Morando, Reactivity of metal oxides: Thermal and photochemical dissolution of MO and $\mathrm{MFe}_{4} \mathrm{O}_{4}(\mathrm{M}=\mathrm{Ni}, \mathrm{Co}, \mathrm{Zn})$, J. Solid State Chem. 181(9) (2008) 2350-2358.

[18] O. Taratula, E. Galoppini, D. Wang, D. Chu, Z. Zhang, H. Chen, G. Saraf, Y. Lu, Binding Studies of Molecular Linkers to ZnO and MgZnO Nanotip Films, J. Phys. Chem. B 110(13) (2006) 6506-6515.

[19] C.G. Allen, D.J. Baker, J.M. Albin, H.E. Oertli, D.T. Gillaspie, D.C. Olson, T.E. Furtak, R.T. Collins, Surface Modification of ZnO Using Triethoxysilane-Based Molecules, Langmuir 24(23) (2008) 13393-13398.

[20] X. Pang, L. Zhao, W. Han, X. Xin, Z. Lin, A general and robust strategy for the synthesis of nearly monodisperse colloidal nanocrystals, Nat Nano 8(6) (2013) 426-431. 
[21] J. Yuan, Y. Xu, A. Walther, S. Bolisetty, M. Schumacher, H. Schmalz, M. Ballauff, A.H.E. Muller, Water-soluble organo-silica hybrid nanowires, Nat Mater 7(9) (2008) 718-722.

[22] M. Müllner, J. Yuan, S. Weiss, A. Walther, M. Förtsch, M. Drechsler, A.H.E. Müller, Water-Soluble Organo-Silica Hybrid Nanotubes Templated by Cylindrical Polymer Brushes, J. Am. Chem. Soc. 132(46) (2010) 16587-16592.

[23] Z. Zheng, A. Daniel, W. Yu, B. Weber, J. Ling, A.H.E. Müller, Rare-Earth Metal Cations Incorporated Silica Hybrid Nanoparticles Templated by Cylindrical Polymer Brushes, Chem. Mater. 25(22) (2013) 4585-4594.

[24] M. He, X. Pang, X. Liu, B. Jiang, Y. He, H. Snaith, Z. Lin, Monodisperse Dual-Functional Upconversion Nanoparticles Enabled Near-Infrared Organolead Halide Perovskite Solar Cells, Angew. Chem. Int. Ed. 55(13) (2016) $4280-4284$.

[25] M. Wang, X. Pang, D. Zheng, Y. He, L. Sun, C. Lin, Z. Lin, Nonepitaxial growth of uniform and precisely size-tunable core/shell nanoparticles and their enhanced plasmon-driven photocatalysis, Journal of Materials Chemistry A 4(19) (2016) 7190-7199.

[26] H. Xu, Y. Xu, X. Pang, Y. He, J. Jung, H. Xia, Z. Lin, A general route to nanocrystal kebabs periodically assembled on stretched flexible polymer shish, Science advances 1(2) (2015) e1500025.

[27] B. Jiang, X. Pang, B. Li, Z. Lin, Organic-Inorganic Nanocomposites via Placing Monodisperse Ferroelectric Nanocrystals in Direct and Permanent Contact with Ferroelectric Polymers, J. Am. Chem. Soc. 137(36) (2015) $11760-11767$.

[28] D. Yang, X. Pang, Y. He, Y. Wang, G. Chen, W. Wang, Z. Lin, Precisely Size - Tunable Magnetic/Plasmonic Core/Shell Nanoparticles with Controlled Optical Properties, Angew. Chem. 127(41) (2015) 12259-12264.

[29] H. Xu, X. Pang, Y. He, M. He, J. Jung, H. Xia, Z. Lin, An Unconventional Route to Monodisperse and Intimately Contacted Semiconducting Organic-Inorganic Nanocomposites, Angew. Chem. 127(15) (2015) 4719-4723.

[30] D. Zheng, X. Pang, M. Wang, Y. He, C. Lin, Z. Lin, Unconventional route to hairy plasmonic/semiconductor core/shell nanoparticles with precisely controlled dimensions and their use in solar energy conversion, Chem. Mater. 27(15) (2015) 5271-5278.

[31] C. Feng, X. Pang, Y. He, Y. Chen, G. Zhang, Z. Lin, A versatile strategy for uniform hybrid nanoparticles and nanocapsules, Polym. Chem. 6(29) (2015) 5190-5197.

[32] H. Gao, K. Matyjaszewski, Arm-First Method As a Simple and General Method for Synthesis of Miktoarm Star Copolymers, J. Am. Chem. Soc. 129(38) (2007) 11828-11834.

[33] G. Xie, H. Ding, W.F.M. Daniel, Z. Wang, J. Pietrasik, S.S. Sheiko, K. Matyjaszewski, Preparation of titania nanoparticles with tunable anisotropy and branched structures from core-shell molecular bottlebrushes, Polymer 98 (2016) 481-486.

[34] R. Djalali, S.-Y. Li, M. Schmidt, Amphipolar Core-Shell Cylindrical Brushes as Templates for the Formation of Gold Clusters and Nanowires, Macromolecules 35(11) (2002) 4282-4288.

[35] K. Huang, J. Rzayev, Well-Defined Organic Nanotubes from Multicomponent Bottlebrush Copolymers, J. Am. Chem. Soc. 131(19) (2009) 6880-6885.

[36] M. Müllner, T. Lunkenbein, J. Breu, F. Caruso, A.H.E. Müller, Template-Directed Synthesis of Silica Nanowires and Nanotubes from Cylindrical Core-Shell Polymer Brushes, Chem. Mater. 24(10) (2012) 1802-1810.

[37] M. Müllner, T. Lunkenbein, M. Schieder, A.H. Gröschel, N. Miyajima, M. Förtsch, J. Breu, F. Caruso, A.H.E. Müller, Template-Directed Mild Synthesis of Anatase Hybrid Nanotubes within Cylindrical Core-Shell-Corona Polymer Brushes, Macromolecules 45(17) (2012) 6981-6988.

[38] J. Yuan, Y. Xu, A. Walther, S. Bolisetty, M. Schumacher, H. Schmalz, M. Ballauff, A.H. Müller, Water-soluble organo-silica hybrid nanowires, Nat. Mater. 7(9) (2008) 718-722.

[39] J. Yuan, Y. Lu, F. Schacher, T. Lunkenbein, S. Weiss, H. Schmalz, A.H. Müller, Template-Directed Synthesis of Hybrid Titania Nanowires within Core- Shell Bishydrophilic Cylindrical Polymer Brushes, Chem. Mater. 21(18) (2009) 4146-4154.

[40] J. Yuan, F. Schacher, M. Drechsler, A. Hanisch, Y. Lu, M. Ballauff, A.H.E. Müller, Stimuli-Responsive Organosilica Hybrid Nanowires Decorated with Metal Nanoparticles, Chem. Mater. 22(8) (2010) 2626-2634.

[41] J. Yuan, M. Drechsler, Y. Xu, M. Zhang, A.H.E. Müller, Cadmium selenide nanowires within core-shell cylindrical polymer brushes: Synthesis, characterization and the double-loading process, Polymer 49(6) (2008) 1547-1554.

[42] W.L. Leong, P.S. Lee, A. Lohani, Y.M. Lam, T. Chen, S. Zhang, A. Dodabalapur, S. G. Mhaisalkar, Non-Volatile Organic Memory Applications Enabled by In Situ Synthesis of Gold Nanoparticles in a Self-Assembled Block Copolymer, Adv. Mater. 20(12) (2008) 2325-2331.

[43] H. Gao, N.V. Tsarevsky, K. Matyjaszewski, Synthesis of Degradable Miktoarm Star Copolymers via Atom Transfer Radical Polymerization, Macromolecules 38(14) (2005) 5995-6004.

[44] J. Xia, K. Matyjaszewski, Controlled/“Living” Radical Polymerization. Atom Transfer Radical Polymerization Catalyzed by Copper(I) and Picolylamine Complexes, Macromolecules 32(8) (1999) 2434-2437. 
[45] K. Matyjaszewski, H. Dong, W. Jakubowski, J. Pietrasik, A. Kusumo, Grafting from Surfaces for "Everyone": ARGET ATRP in the Presence of Air, Langmuir 23(8) (2007) 4528-4531.

[46] W. Jakubowski, K. Min, K. Matyjaszewski, Activators Regenerated by Electron Transfer for Atom Transfer Radical Polymerization of Styrene, Macromolecules 39(1) (2006) 39-45.

[47] W. Jakubowski, K. Matyjaszewski, Activators Regenerated by Electron Transfer for Atom-Transfer Radical Polymerization of (Meth)acrylates and Related Block Copolymers, Angew. Chem. Int. Ed. 45(27) (2006) 4482-4486.

[48] J. Pietrasik, C.M. Hui, W. Chaladaj, H. Dong, J. Choi, J. Jurczak, M.R. Bockstaller, K. Matyjaszewski, Silica-Polymethacrylate Hybrid Particles Synthesized Using High-Pressure Atom Transfer Radical Polymerization, Macromol. Rapid Commun. 32(3) (2011) 295-301.

[49] K. Ohno, K. Koh, Y. Tsujii, T. Fukuda, Fabrication of Ordered Arrays of Gold Nanoparticles Coated with High-Density Polymer Brushes, Angew. Chem. Int. Ed. 42(24) (2003) 2751-2754.

[5o] F. Vietmeyer, B. Seger, P.V. Kamat, Anchoring ZnO particles on functionalized single wall carbon nanotubes. Excited state interactions and charge collection, Adv. Mater. 19(19) (2007) 2935-2940.

[51] N.V. Tsarevsky, T. Sarbu, B. Göbelt, K. Matyjaszewski, Synthesis of Styrene-Acrylonitrile Copolymers and Related Block Copolymers by Atom Transfer Radical Polymerization, Macromolecules 35(16) (2002) 6142-6148.

[52] L. Mueller, W. Jakubowski, W. Tang, K. Matyjaszewski, Successful Chain Extension of Polyacrylate and Polystyrene Macroinitiators with Methacrylates in an ARGET and ICAR ATRP, Macromolecules 40(18) (2007) 6464-6472.

[53] C.-H. Peng, J. Kong, F. Seeliger, K. Matyjaszewski, Mechanism of halogen exchange in ATRP, Macromolecules 44(19) (2011) 7546-7557.

[54] W. Li, K. Matyjaszewski, Star Polymers via Cross-Linking Amphiphilic Macroinitiators by AGET ATRP in Aqueous Media, J. Am. Chem. Soc. 131(30) (2009) 10378-10379.

[55] H. Gao, K. Matyjaszewski, Synthesis of functional polymers with controlled architecture by CRP of monomers in the presence of cross-linkers: From stars to gels, Prog. Polym. Sci. 34(4) (2009) 317-350.

[56] H. Gao, K. Matyjaszewski, Synthesis of Star Polymers by a Combination of ATRP and the "Click" Coupling Method, Macromolecules 39(15) (2006) 4960-4965.

[57] M. Epifani, J. Arbiol, R. Díaz, M.J. Perálvarez, P. Siciliano, J.R. Morante, Synthesis of $\mathrm{SnO}_{2}$ and ZnO Colloidal Nanocrystals from the Decomposition of Tin(II) 2-Ethylhexanoate and Zinc(II) 2-Ethylhexanoate, Chem. Mater. $17(25)$ (2005) 6468-6472. 